دراسات في آثار الوطن العربي

$$
\begin{aligned}
& \text { الآثار العربية في زنجبار دراسة معمارية }
\end{aligned}
$$

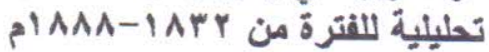

$$
\begin{aligned}
& \text { أ. حسن محمد عبد الله" }
\end{aligned}
$$

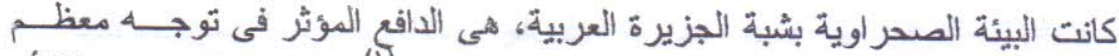

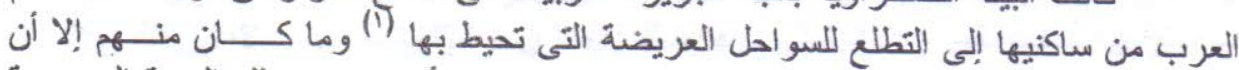

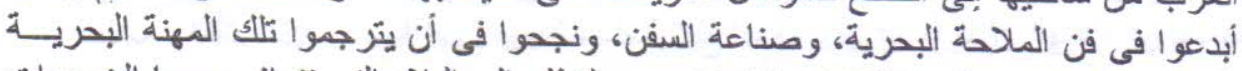

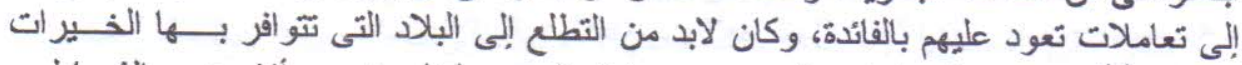

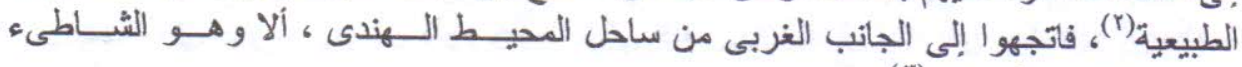

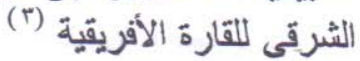

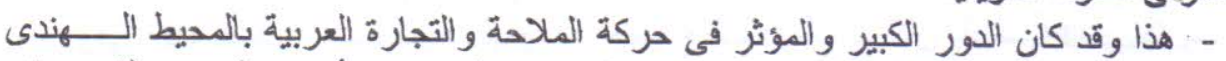

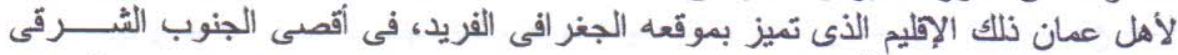

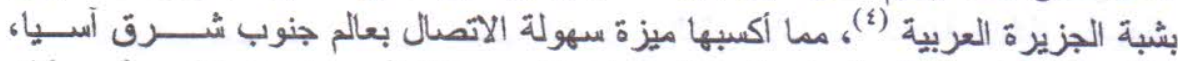

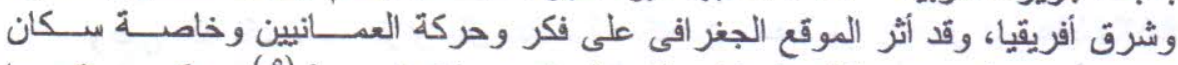

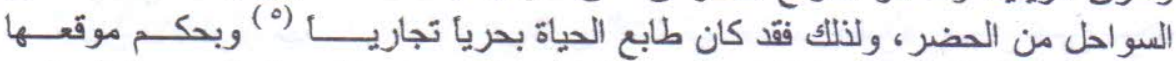

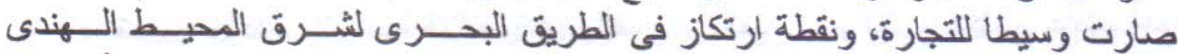

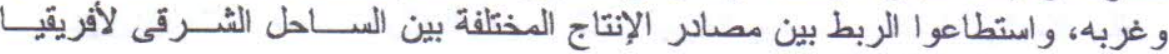

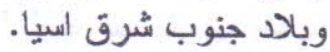

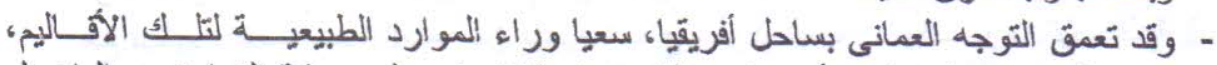

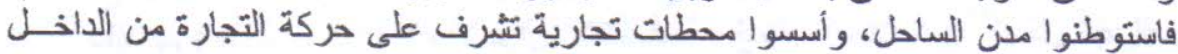

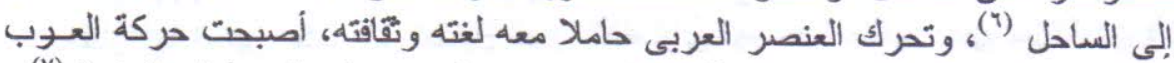

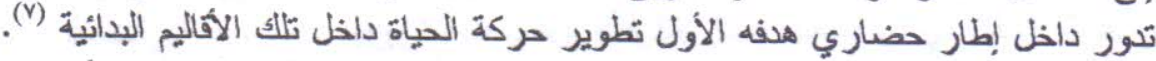

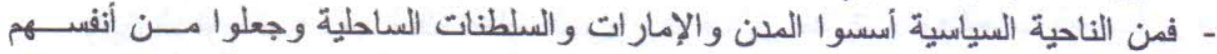

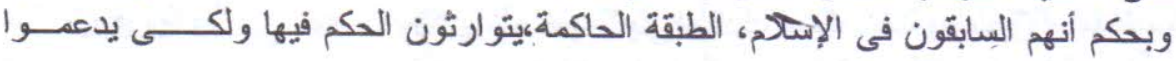

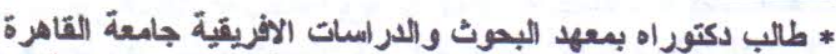

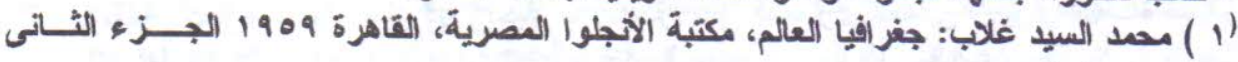

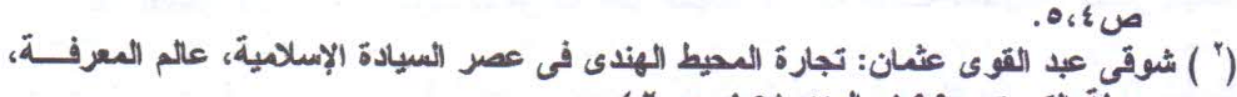
( ${ }^{3}$ Basil Davidrson: the Loste cities of Africa U.S.A 1959. P. 199.

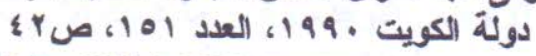

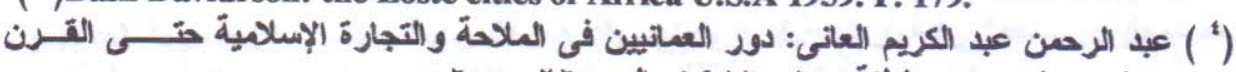

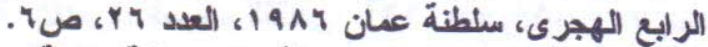

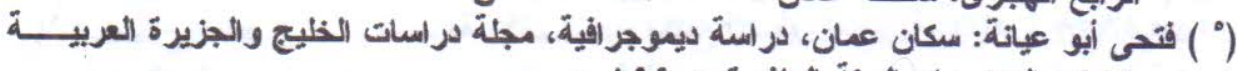

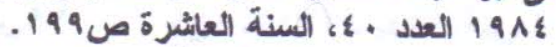

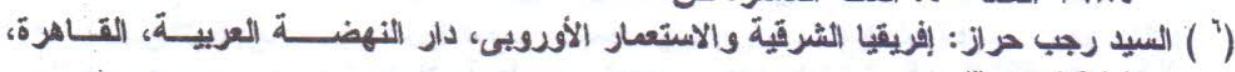

( ${ }^{7}$ ) Couplant, dr: East Africa and its invaders from the earlest times to the Siyyd Said in 1856, Oxford, 1938 ,P.8. 
دراسات في آثار الوطن العربي

نفوذهم ويؤمنو ا ظهور هم حافظوا على العلاقات الوثيقة بينهم وبين الوطن الأم فى عمسان

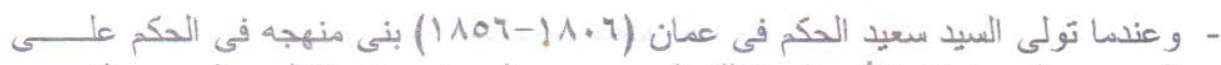

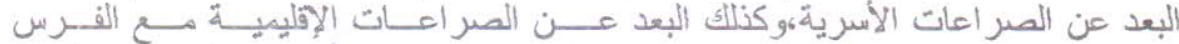

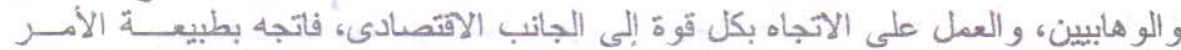

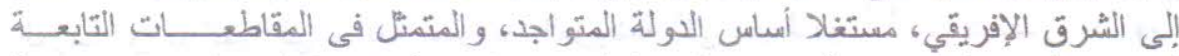

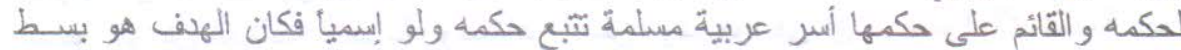

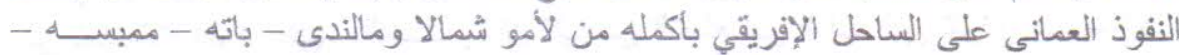
بمبة - زنجبار -- مفيه - كلوه جنوبا، حتى خلص له له الشرق الإفريقي سياسيا و اقتصاديــا

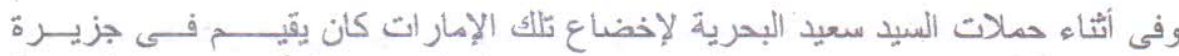

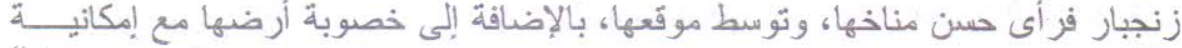

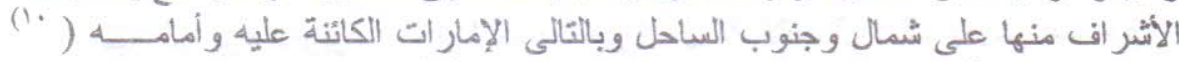

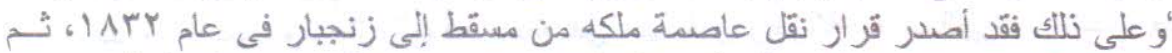

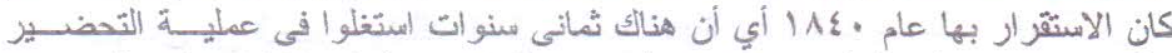

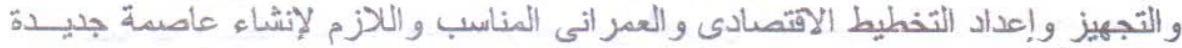

(11) العبطنان

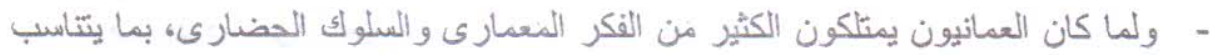

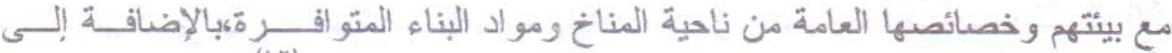

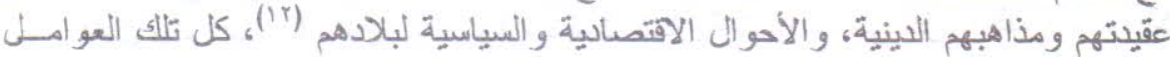

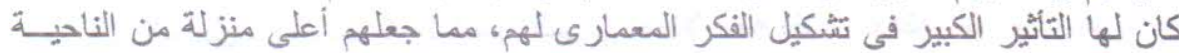

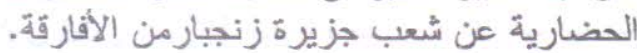

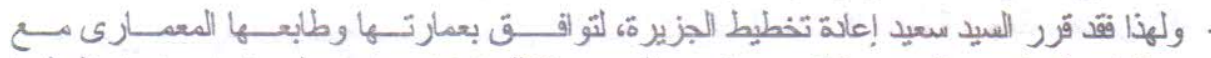

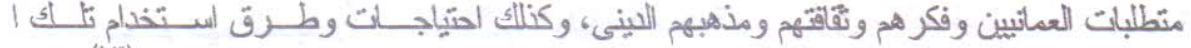

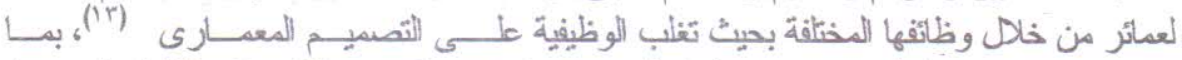

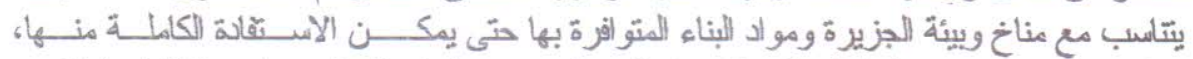

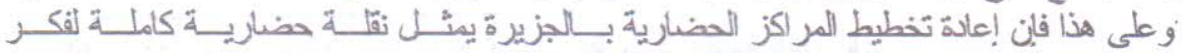

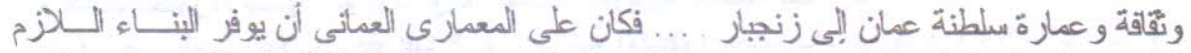

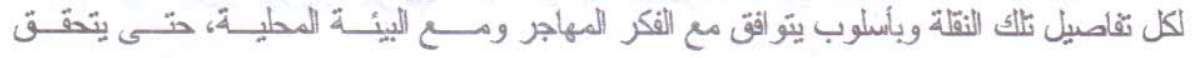

(" ) عبد الرحمن زكى: بعض المدن العريبة على ساحل إفريقية الشرقية فى العصــور المستطي،

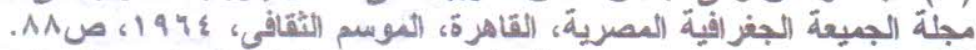

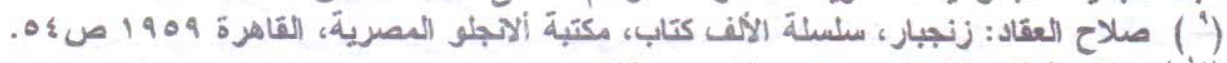

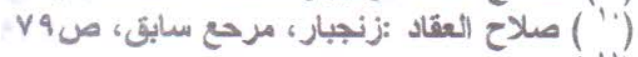

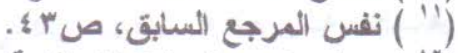

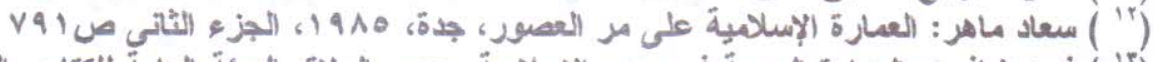
(") ") فريد شافعى: العمارة العريبةً فى مصر الإسلامية، عصر اللولاة، الهيئة العامة للكتاب، القاهرة

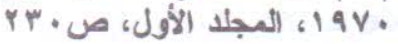


دراسات في آثار الوطن العربي

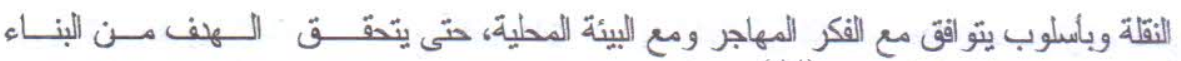

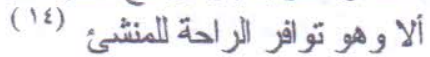

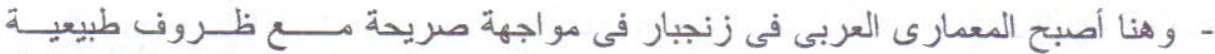

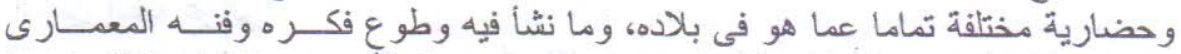

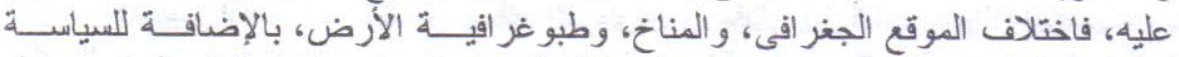

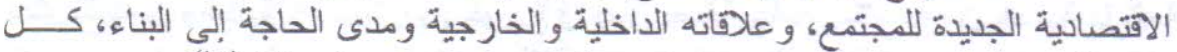

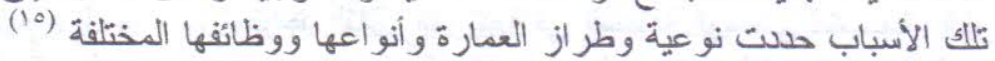

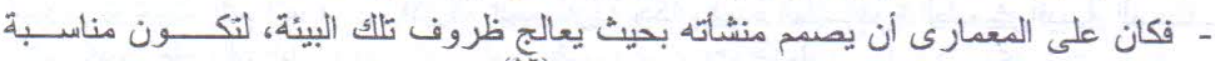

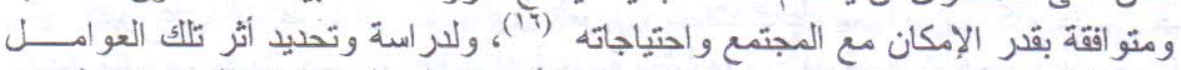

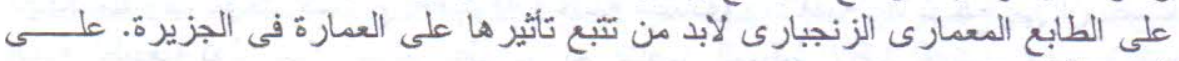

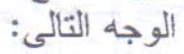

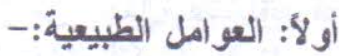

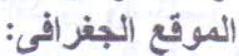

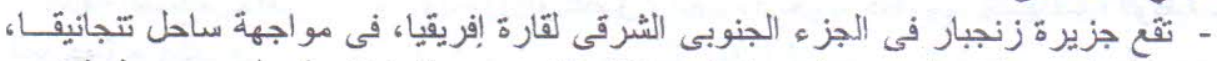

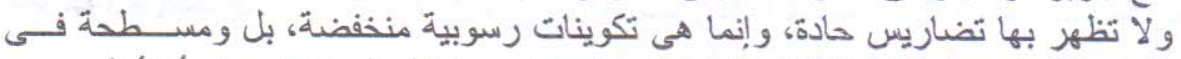

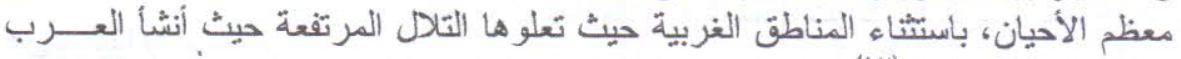

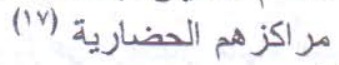

المناخ: مزاخ

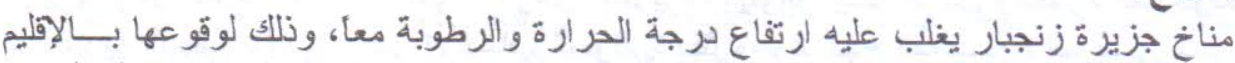

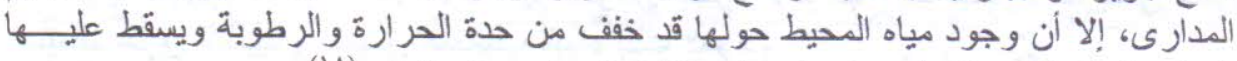

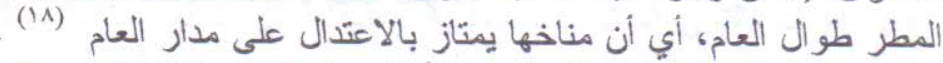

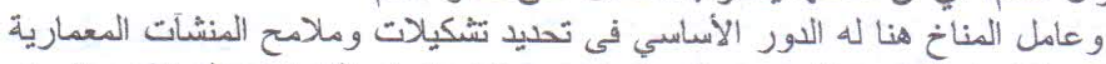

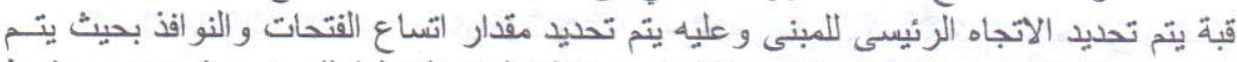

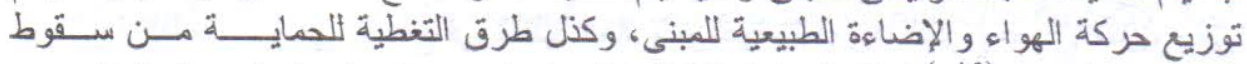

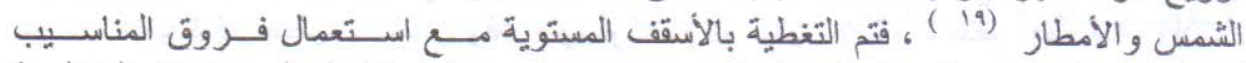

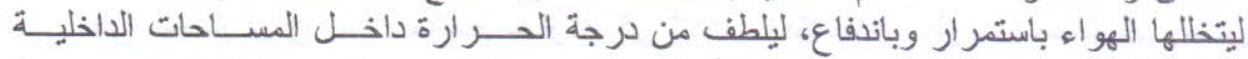

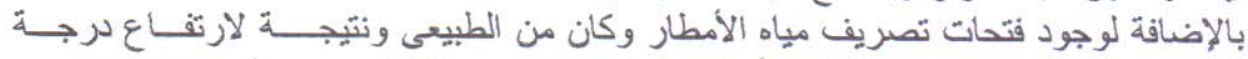

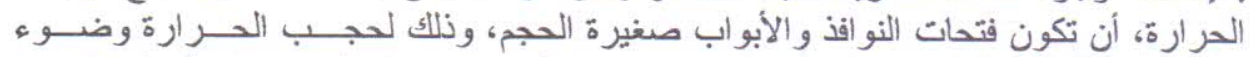

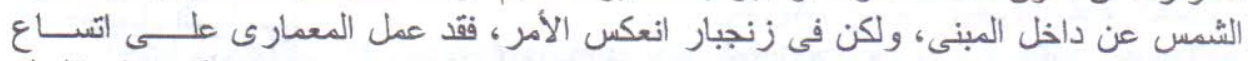

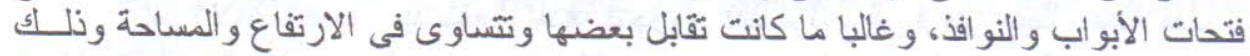

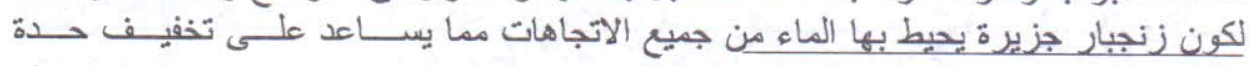

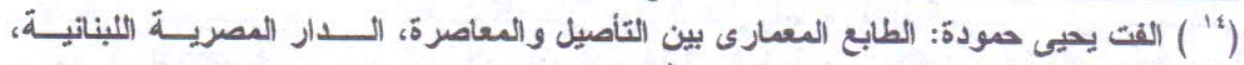

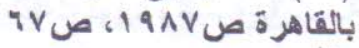

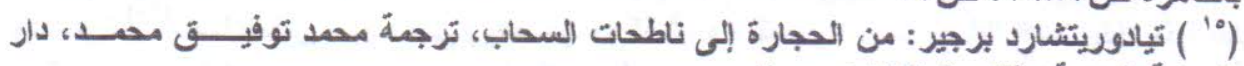

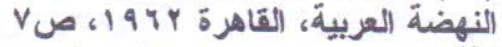

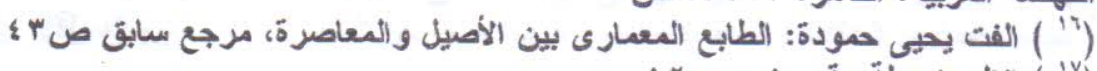

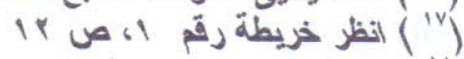

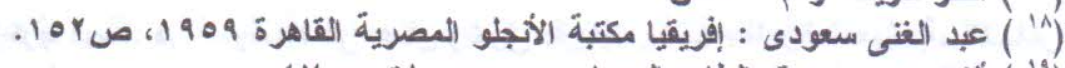

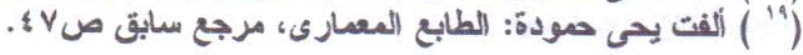


جزيرة يحيط بها الماء من جميع الاتجاهات مما يساعد على تخفيف حدة الحـــرارة وتلطيفـــها بو اسطة تيار ات الهو اءة البحرية.

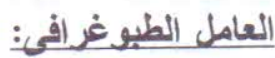

ونعنى به در اسة مظاهر سطح الأرض، أي مقدار الارتفاعات والانخفاضات و علاقة

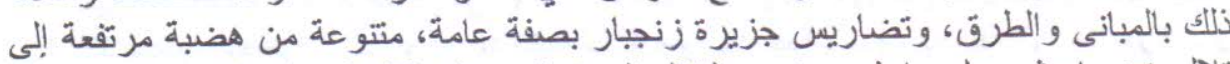

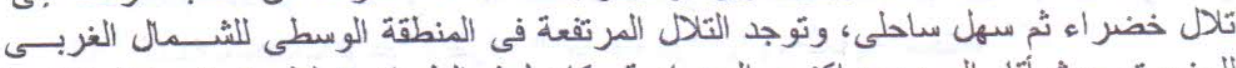

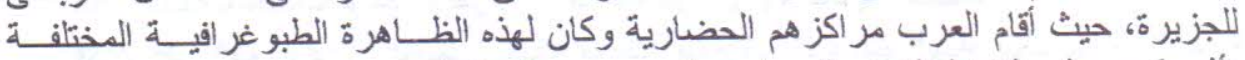

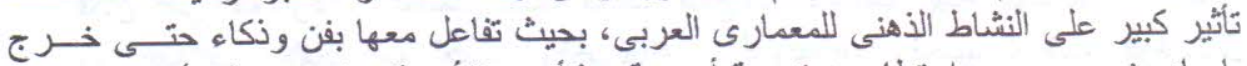

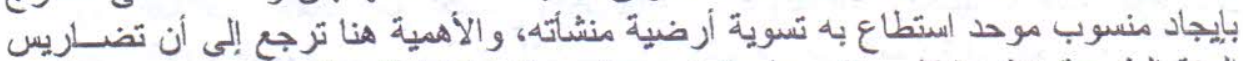

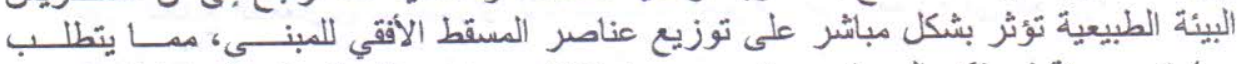

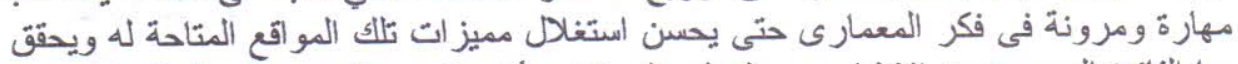

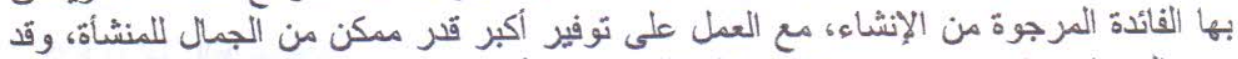

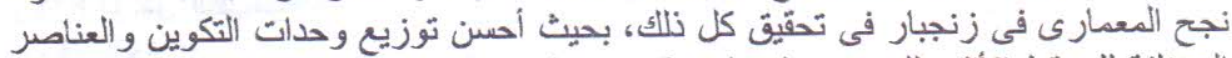

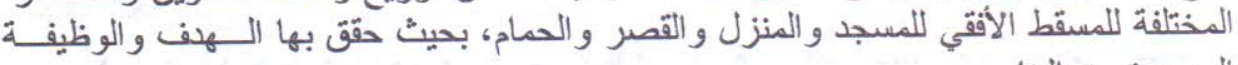
المرجوة من البناء.

هواد الانباء:

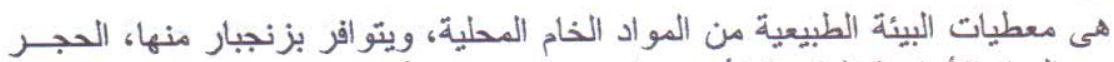

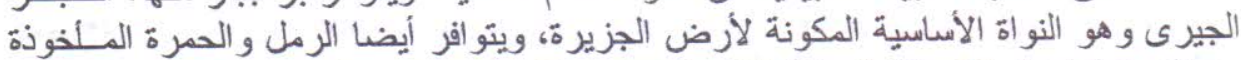

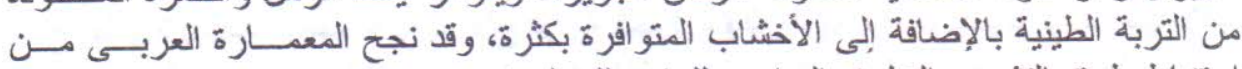

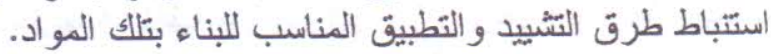

\section{العوامل الحضارية:}

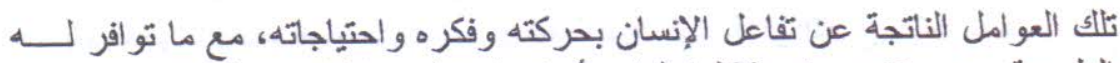

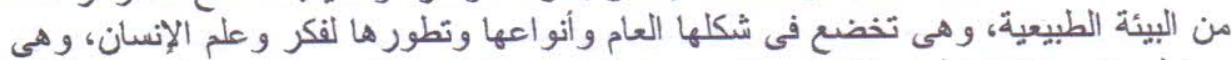

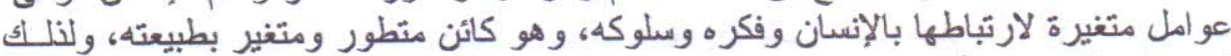

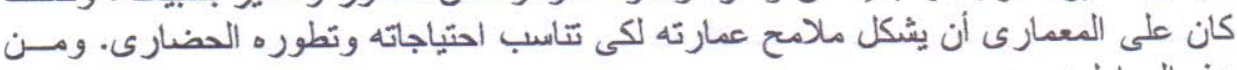

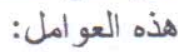

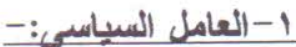

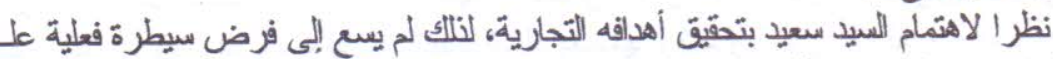

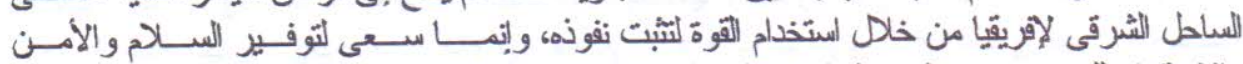

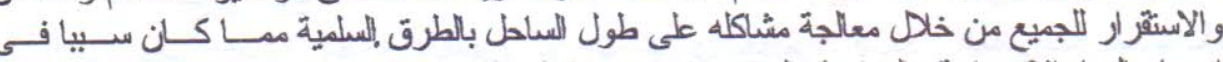

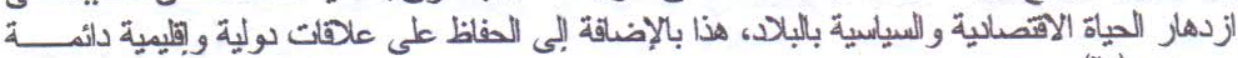

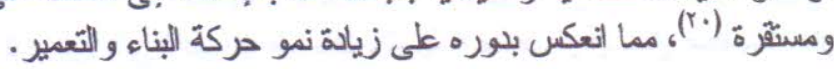

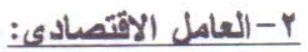

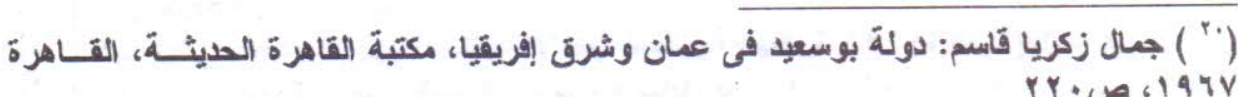


دراسات في آثار الوطن العربي

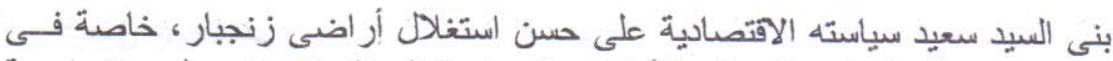

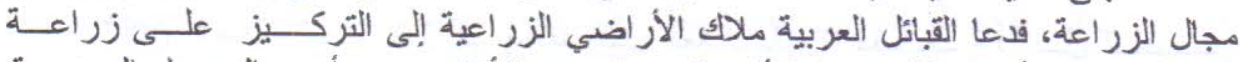

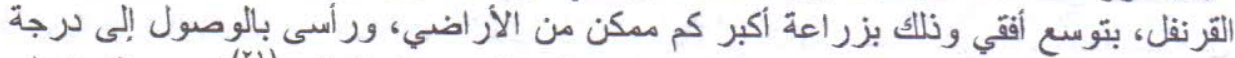

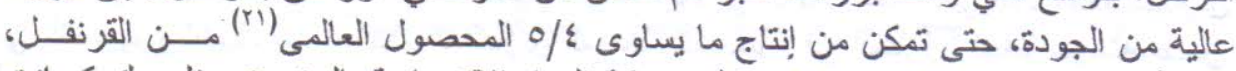

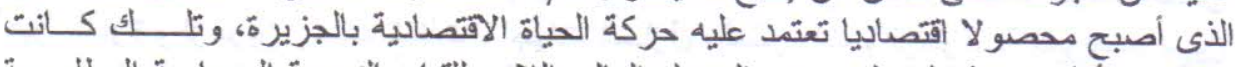

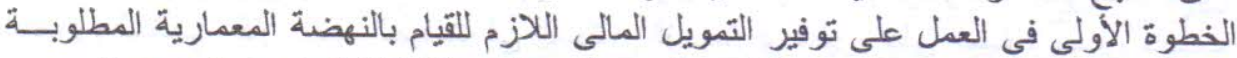

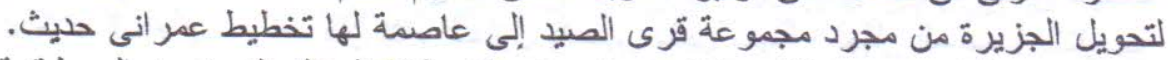

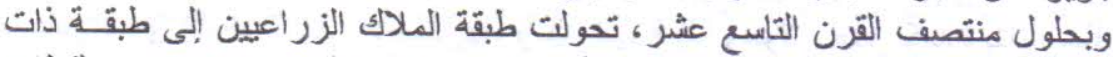

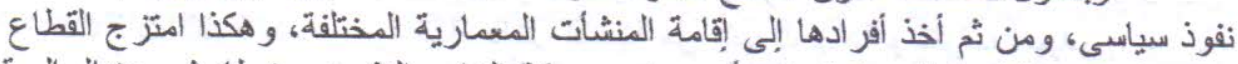

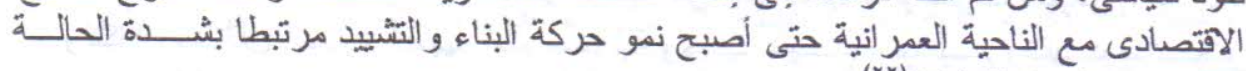

الاقتصادية العامة للسلطنة (rr)

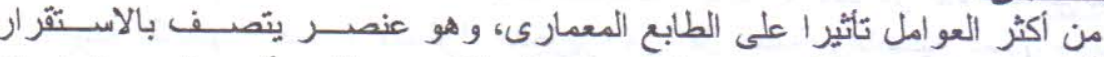

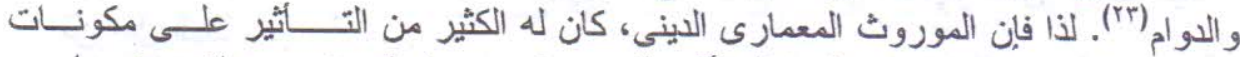

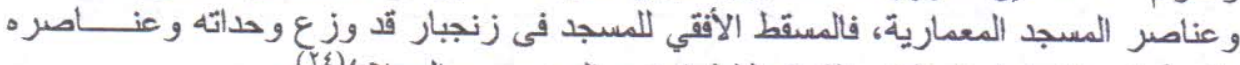

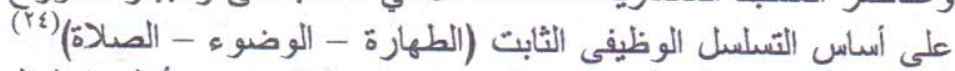

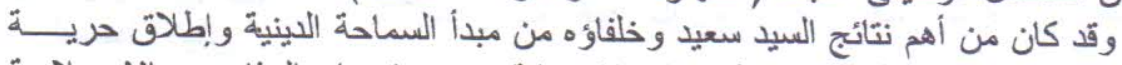

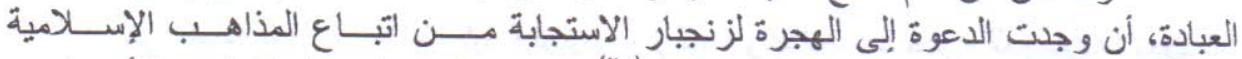

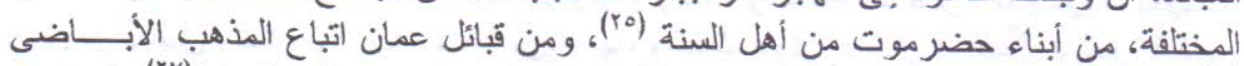

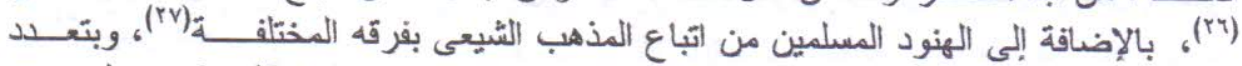

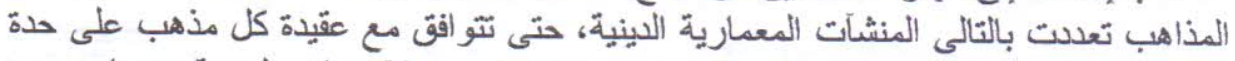

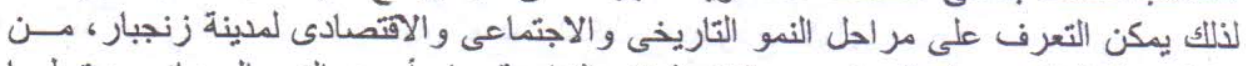

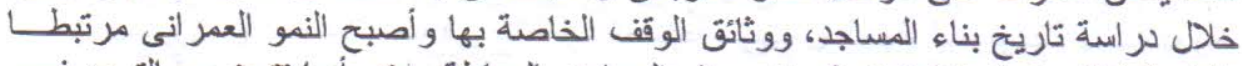

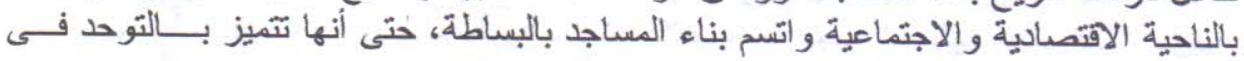
أسلوب البناء و المواد المستخمة.

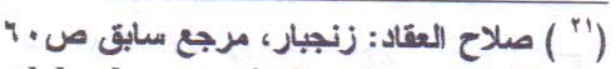
$\left({ }^{22}\right)$ Abdul Shriff, Mosques Merchnts and landawnery in Zangibar, ston Town, Azania,pp5,6

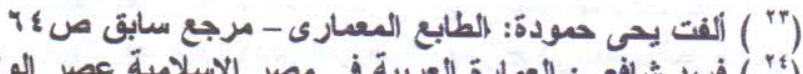

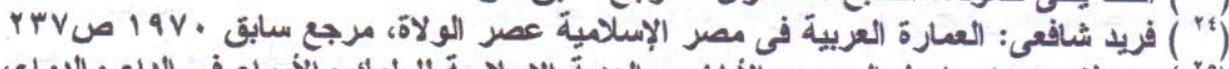

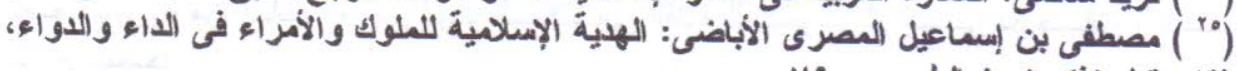

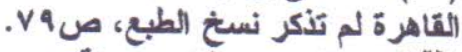

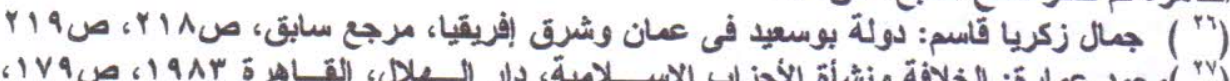

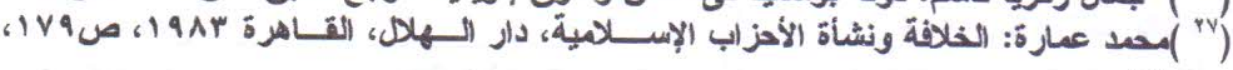
"من اكثر فرق الثشيعة انتثارا فى زنجبار، الشيعة الإسماعيلية "البهرة" والأثى عشرية وقد أقام ص. كل منهم أماكن خاصة لعبادتهم. 


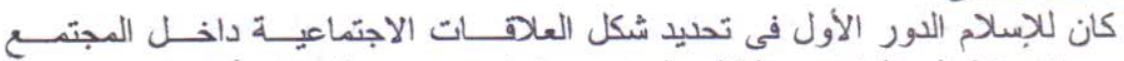

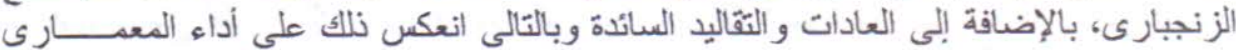

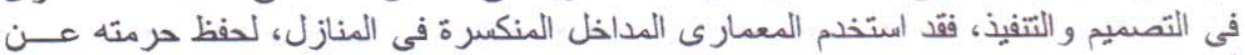

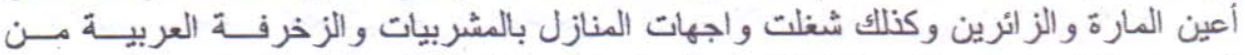

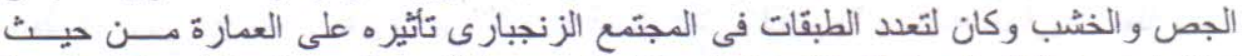

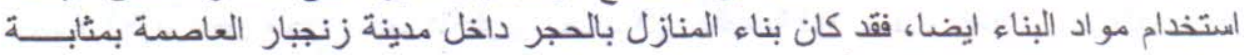

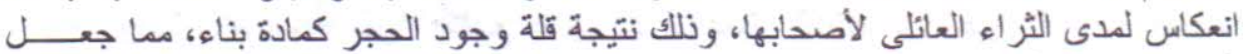

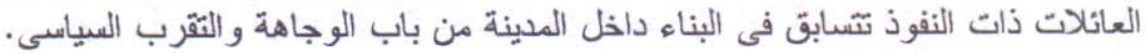

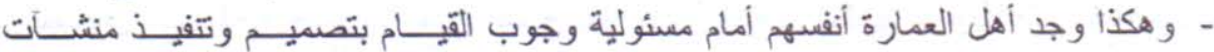

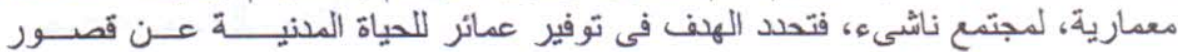

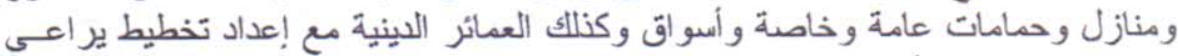

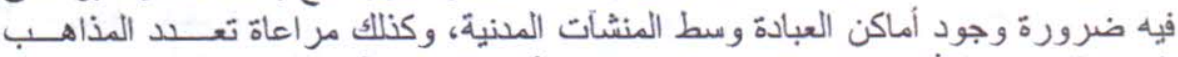

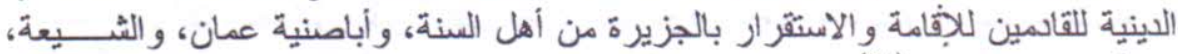

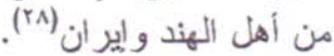

ثُانيا: وحدات التكوين المعمارى: المعة: أ - المسقط الافقيق:

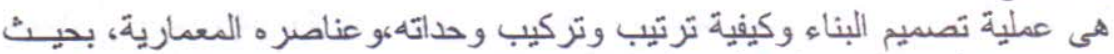

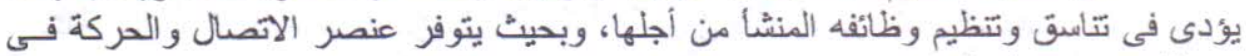
سهولة ويسر داخل البناء.

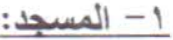

فالمسقط الأفقي للمسجد فى زنجبار تعددت أشكاله، فالنموذج الاول منه:-

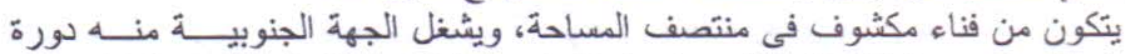

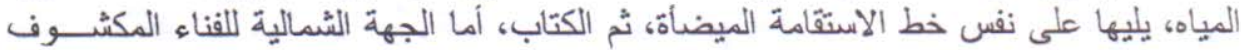

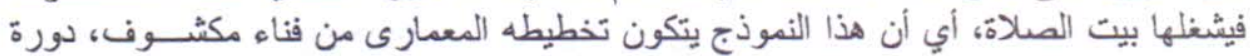

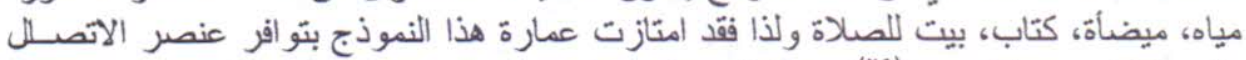

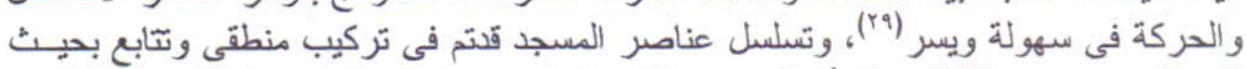

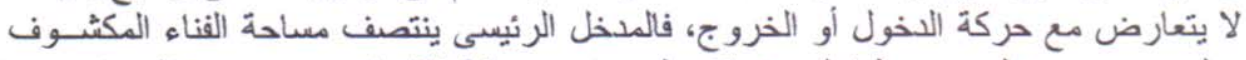

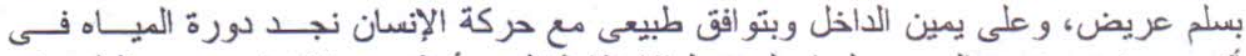

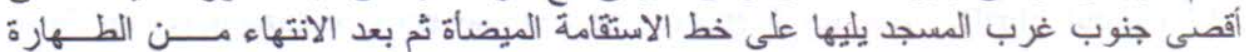

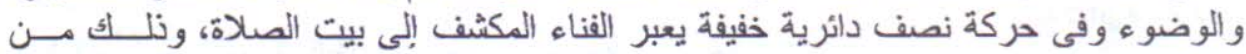

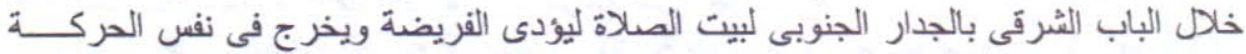

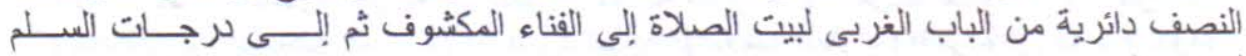

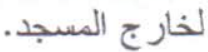

(1^) (معيد بن على المفيرى: جهنية الأخبار فى تاريخ زنجبار، تحقيق عبدالمنعــم عـامر، وزارة

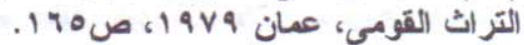

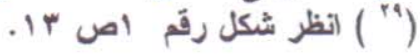


- وفى هذا النموذج يبدو جليا سيطرة الوحدة الرئيسية فى المسقط الأفقي وهى بيت الصـــلاة

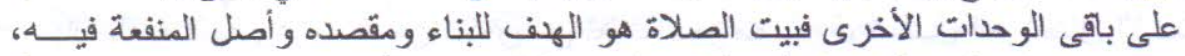

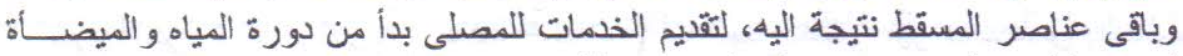

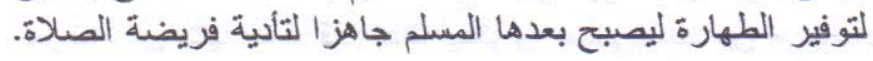

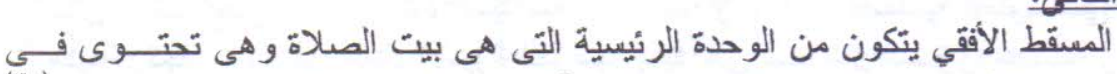
النمونج الثانمى:

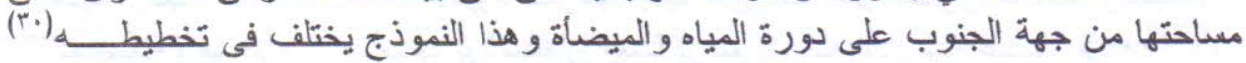

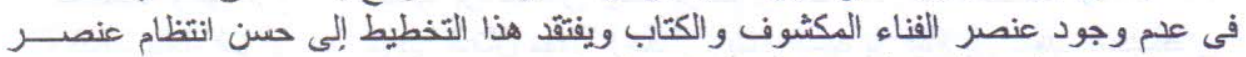

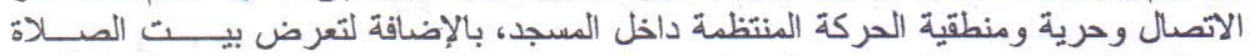

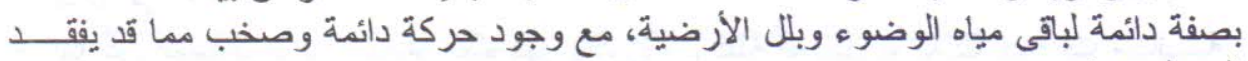
المصلى تركيزه.

\section{النموذج الثالث:}

تخطيطه يرجع إلى نموذج المساجد المعلقة حيث يتكون مسقطه من مستويين الأسفل

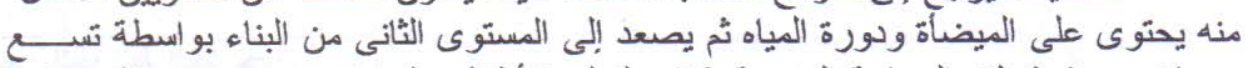

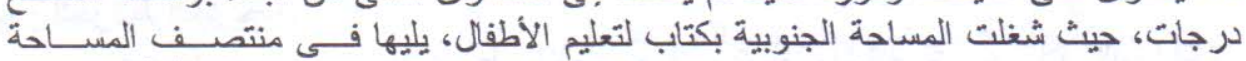

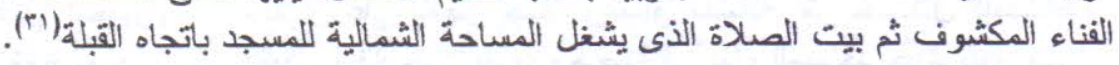

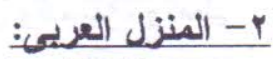

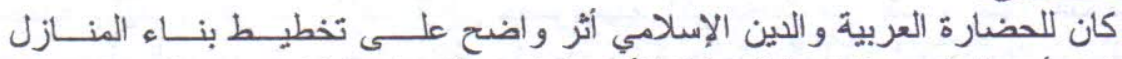

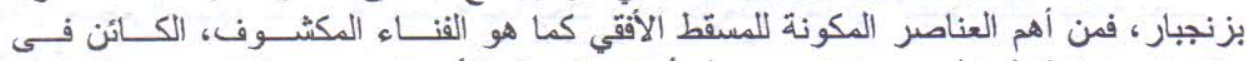

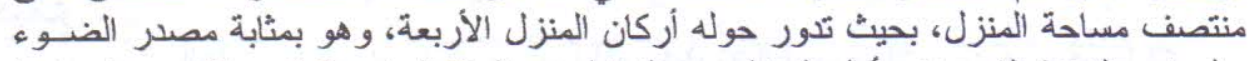

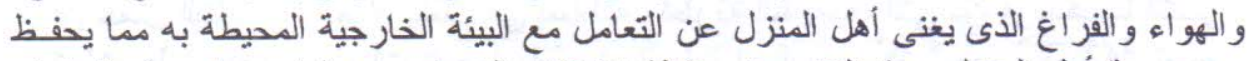

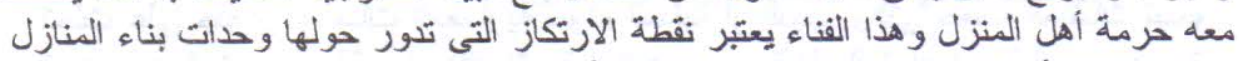

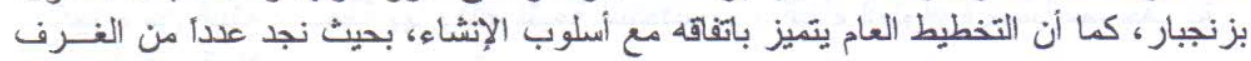

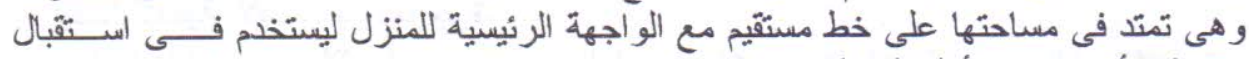

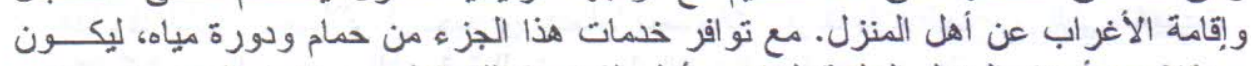

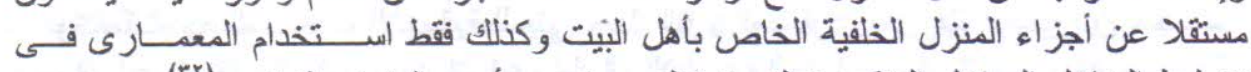

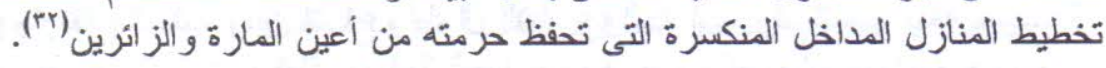

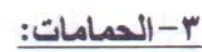

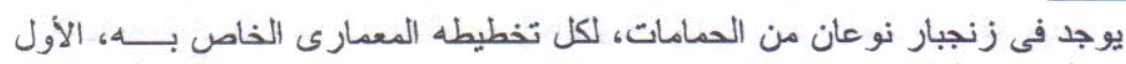

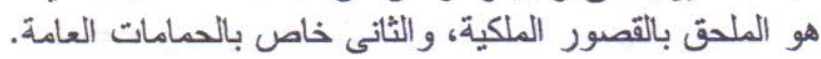

(') $\left({ }^{32}\right)$ The united Nation Center for Human Settlements, the ston Twon of Zangibar, Atechinel report bar the Minastry of lands, construction and Hallsin, Zangibar, April, 1985 P.8-10. 
راسات في آثار الوطن العربي

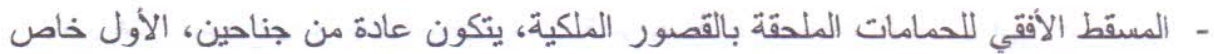

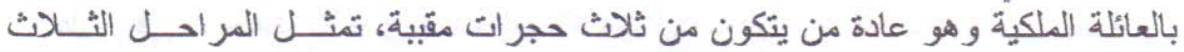

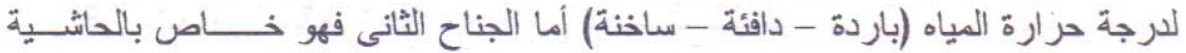

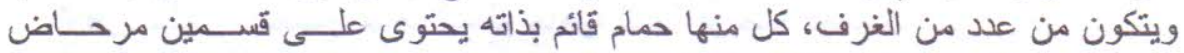

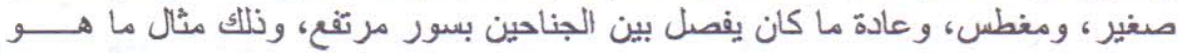

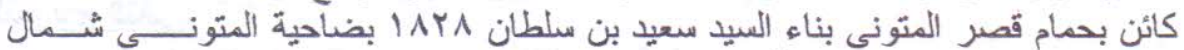

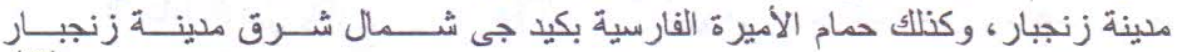

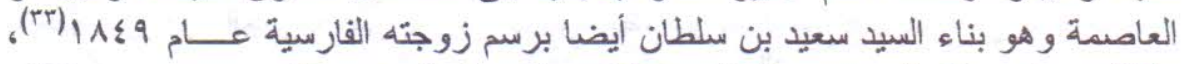

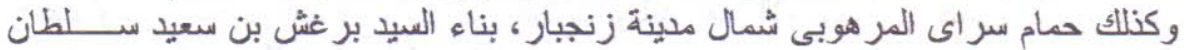

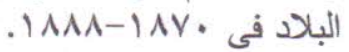

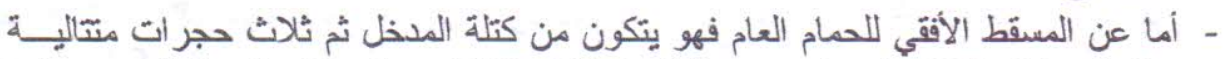

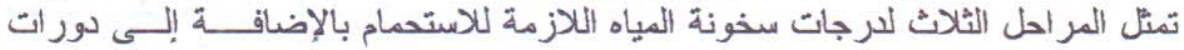

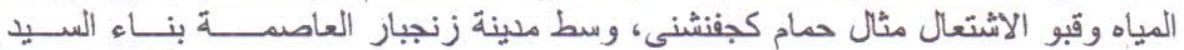
بر غش بن سعيد.

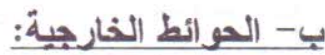

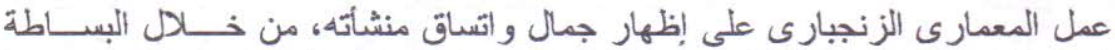

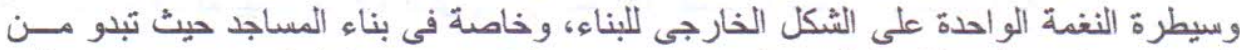

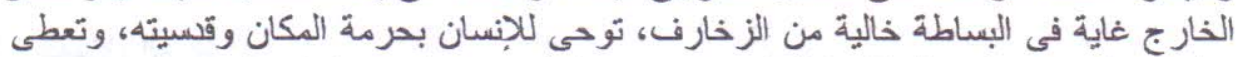

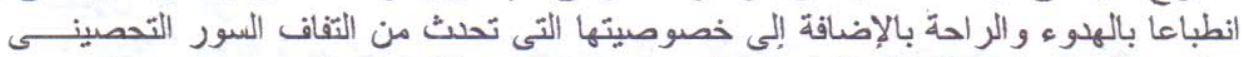

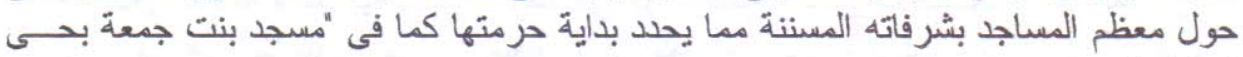

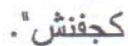

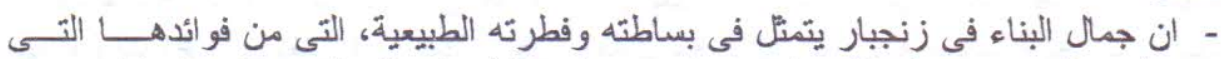

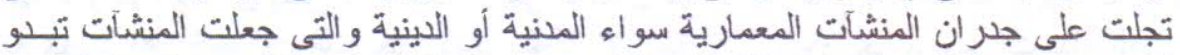

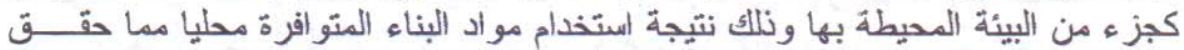

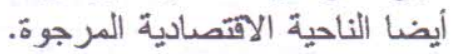

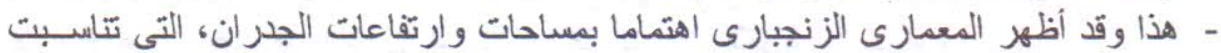

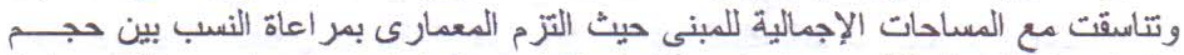

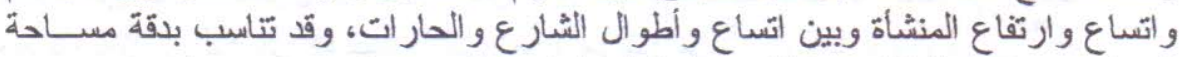

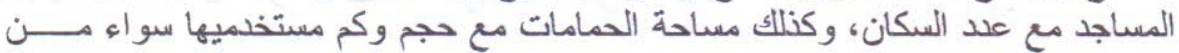

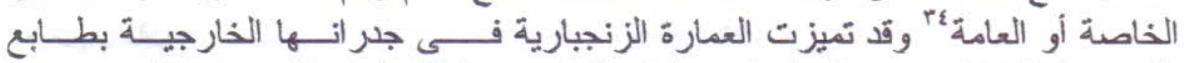

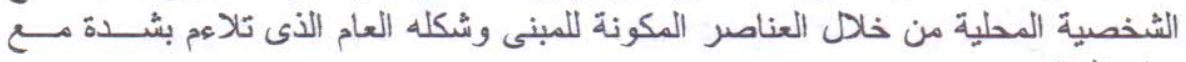

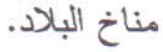

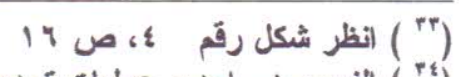

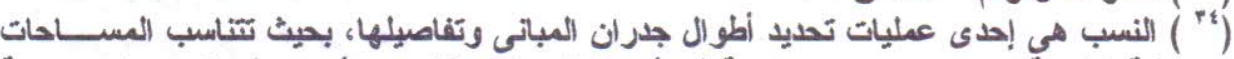

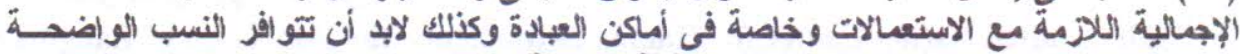

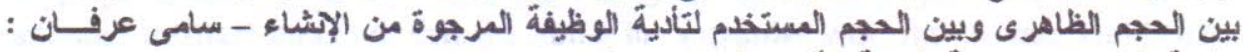

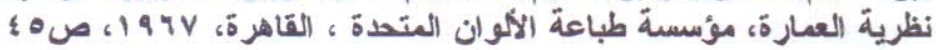




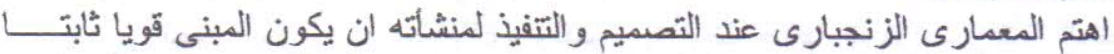

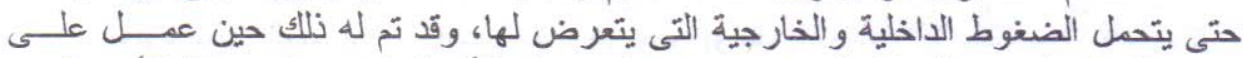

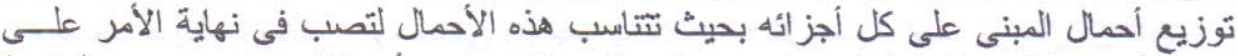

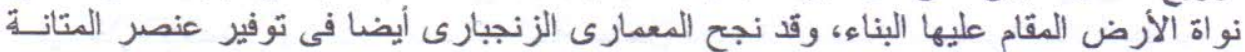

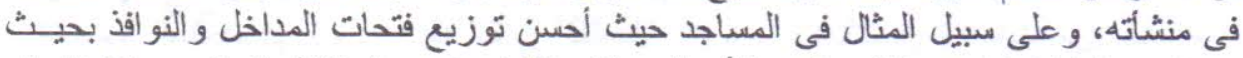

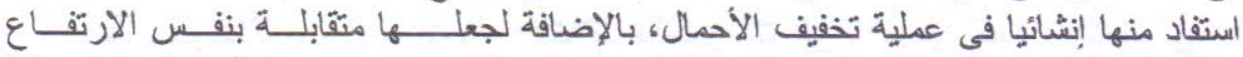

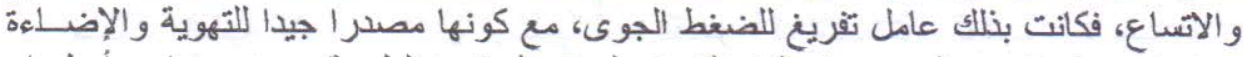

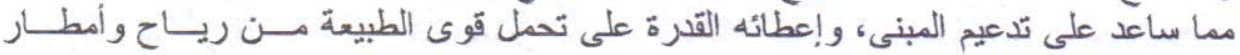
ورطوبة دائمة.

وفى الحمامات نجدان فتحة المدخل فى جناح حمام الأميرة الفارسية بكيد جيى بنــاء

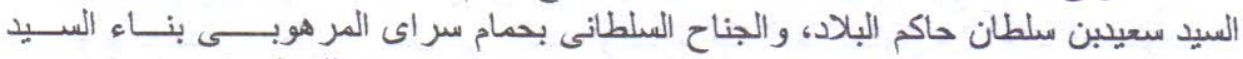

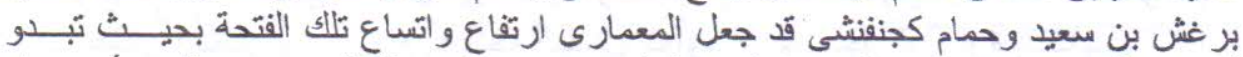

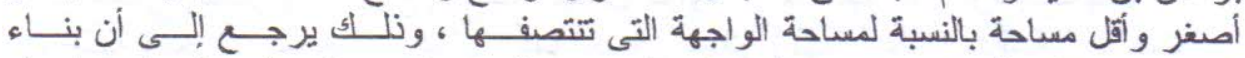

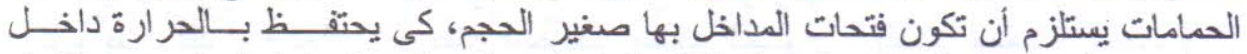
الحمام مع المحافظة على الخصوصية ولذلك فقد استخدم المعمارى المداخل المنكســـرة ليقلـلـل

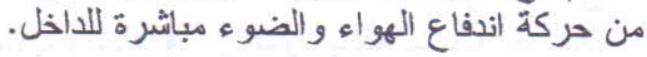

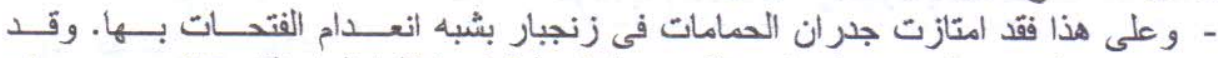

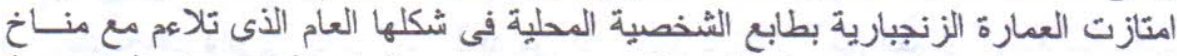

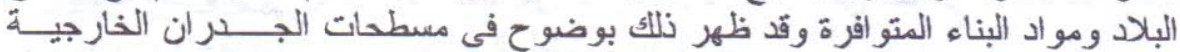

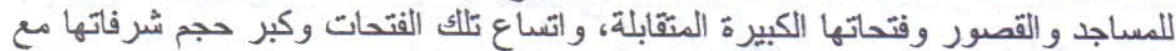

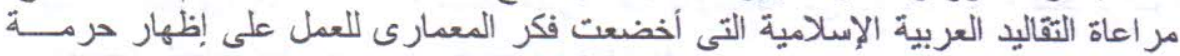

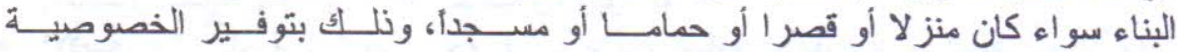
و المحافظة عليها وهى الصفة الرئيسية لمبانى المدنية.

\section{ثُالثاً: العناصر المعماربة:}

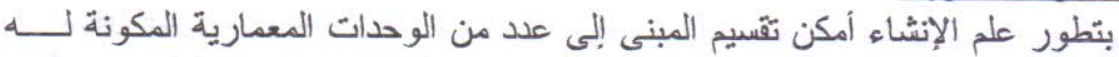

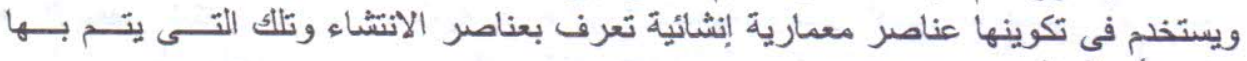

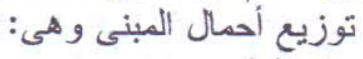

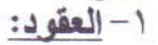

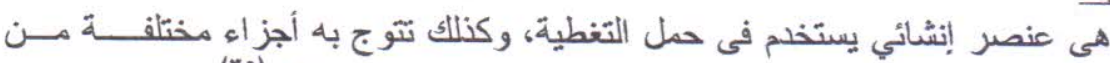

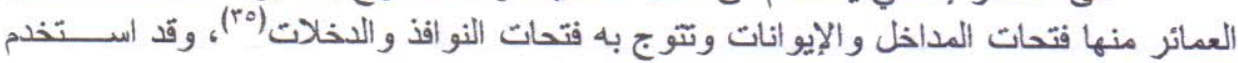

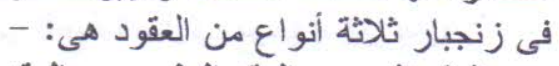

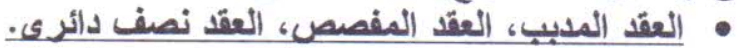

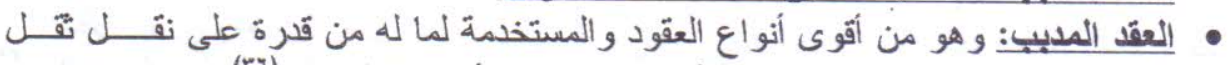

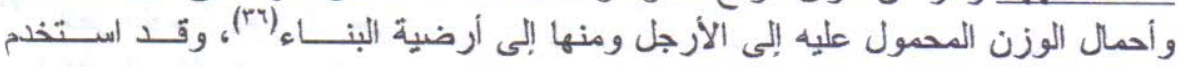

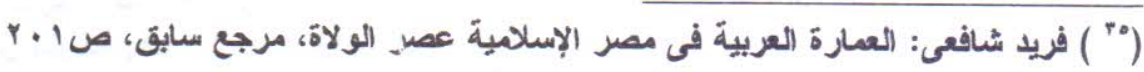


دراسات في آثار الوطن العربي

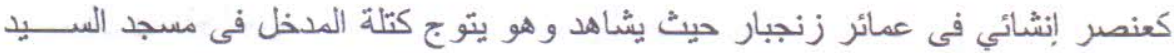

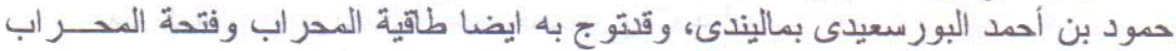

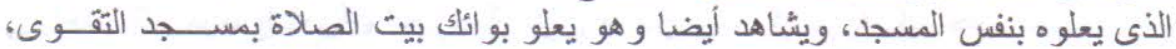

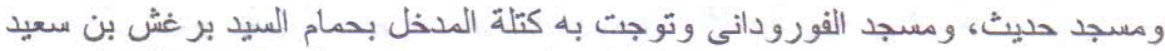

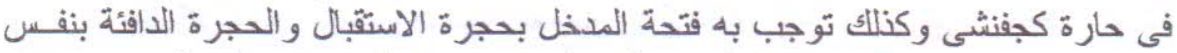

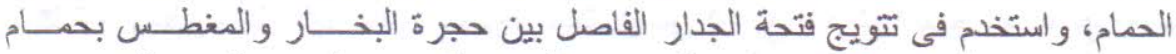

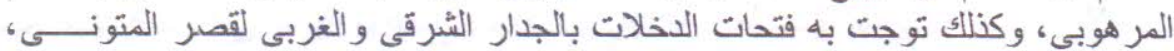

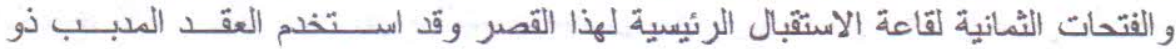

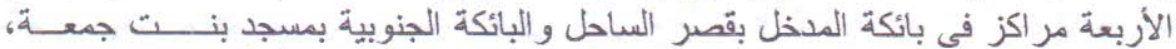

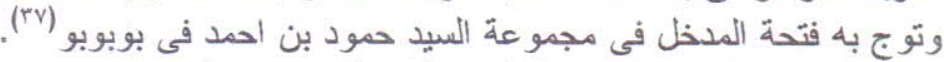

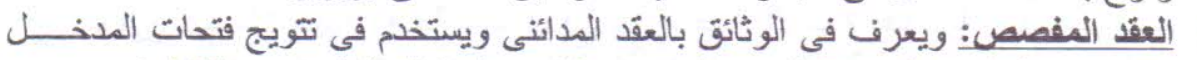

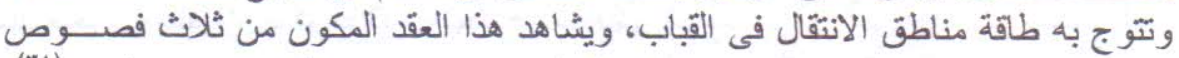

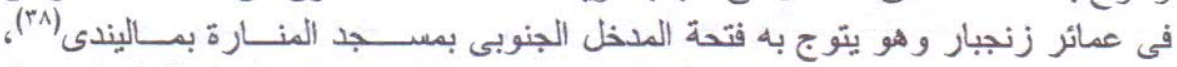

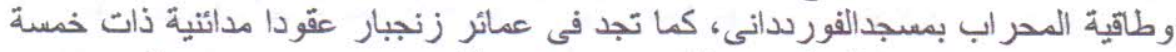

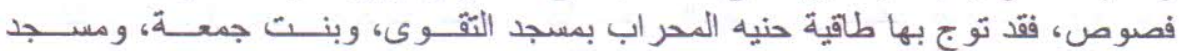

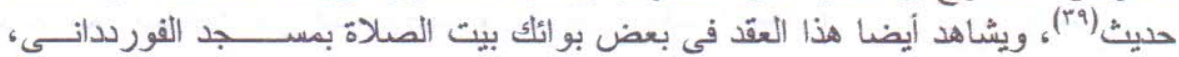

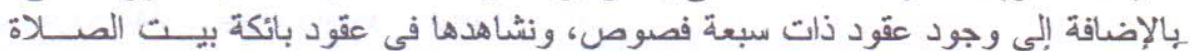

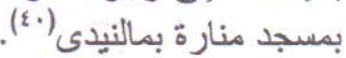

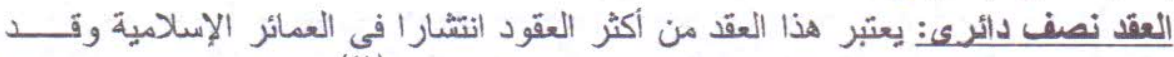

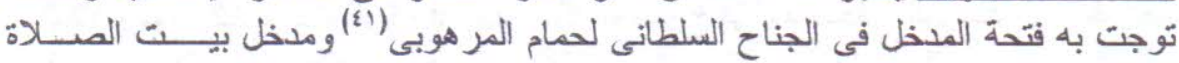

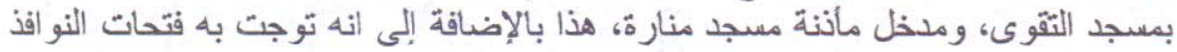

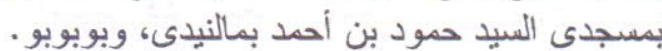

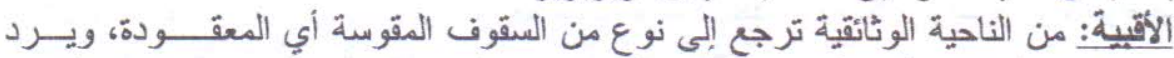

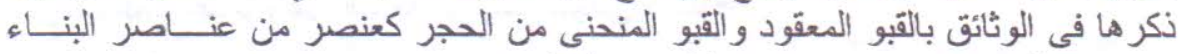

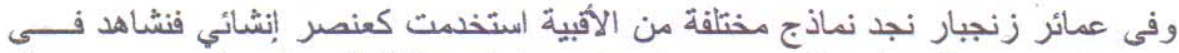

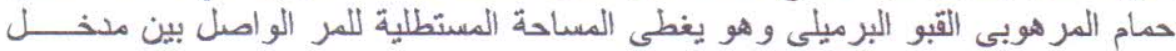

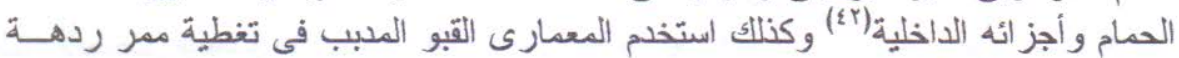

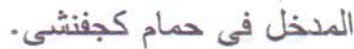

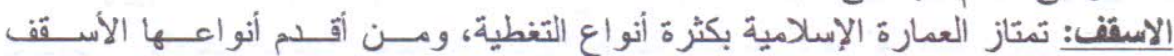

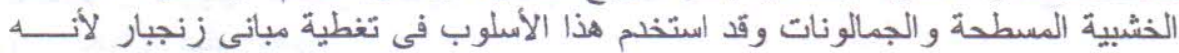

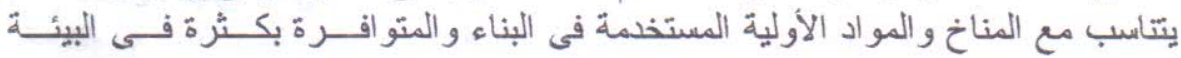

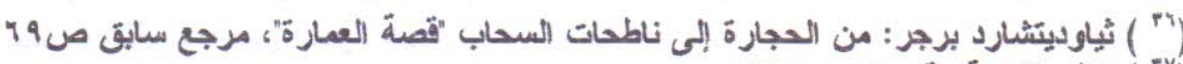

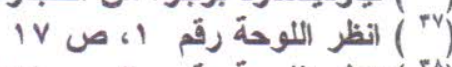

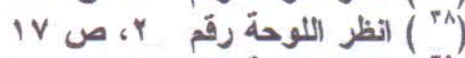

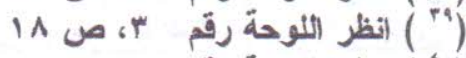

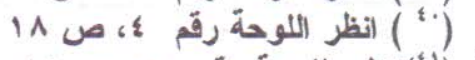

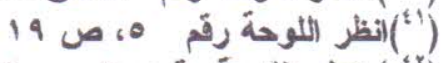

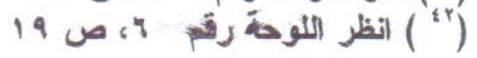


دراسات في آثار الوطن العربي

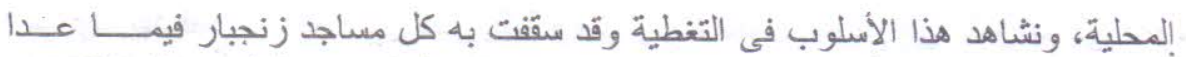

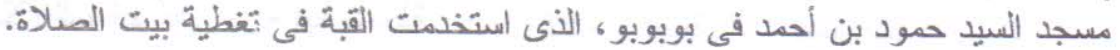
• • مناطق الانتقال: هناك نوعان منها: أ- - المقرنصات:

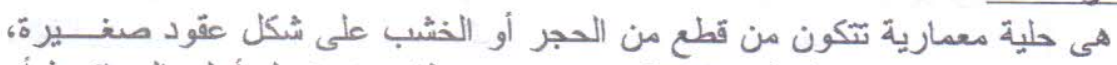

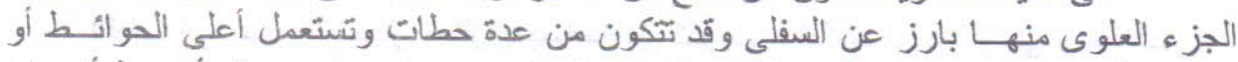

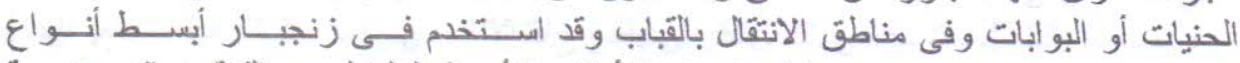

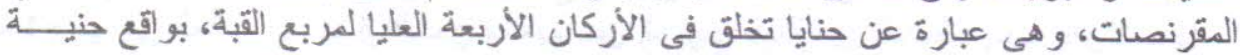

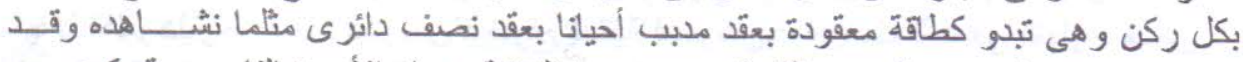

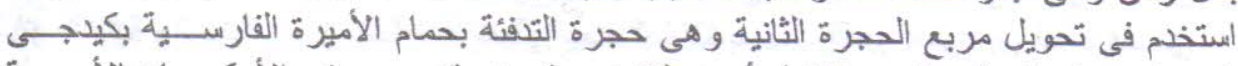

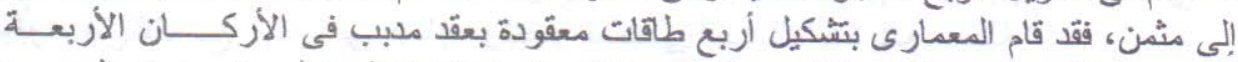

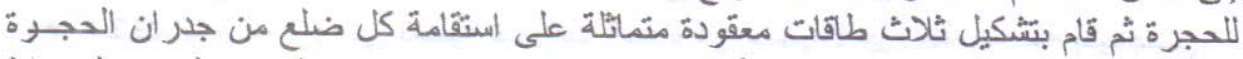

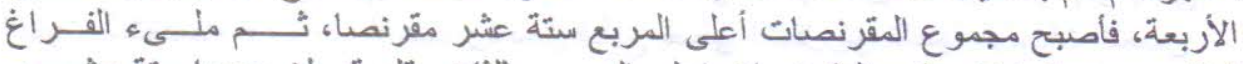

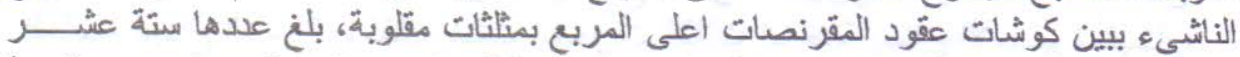

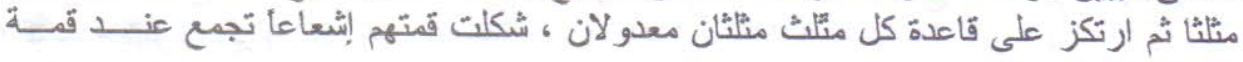

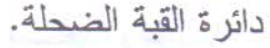

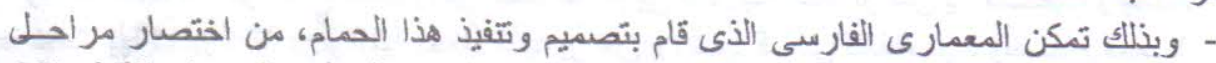

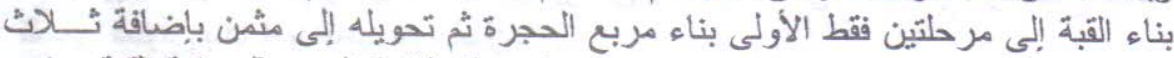

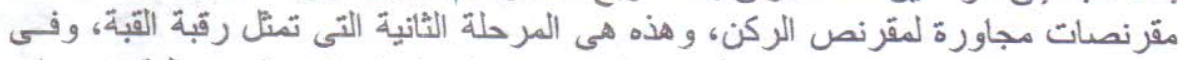

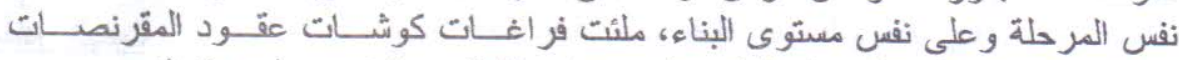

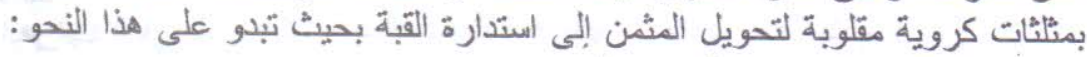
- مدد أربعة مقرنصات فى الأركان الأربعة.

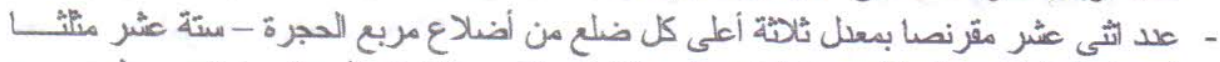

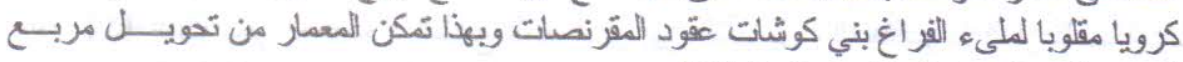
الحجرة إلى مثمن ثُ إلى قاعة دائرية كاملة.

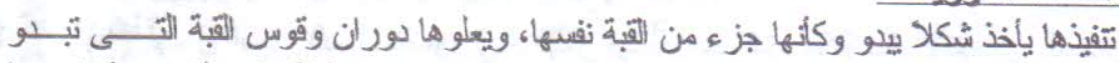

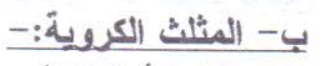

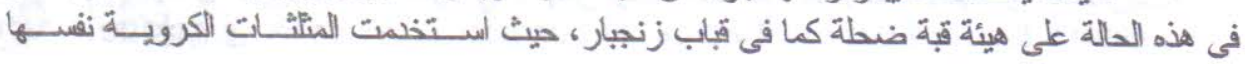
كجزء من قطر التباب التى تحملها.

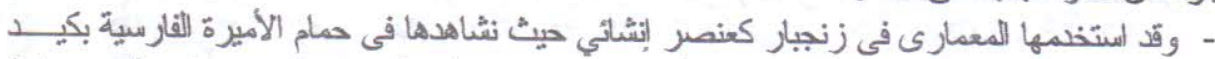

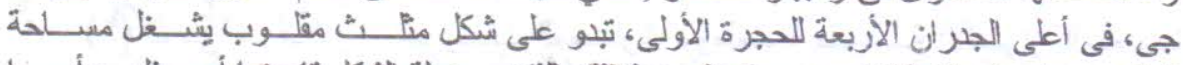

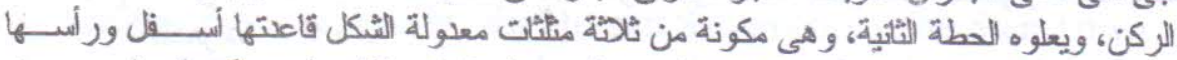

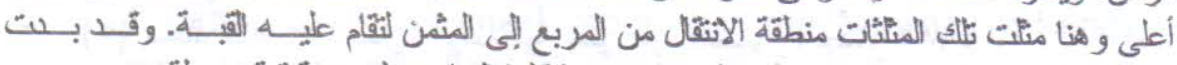

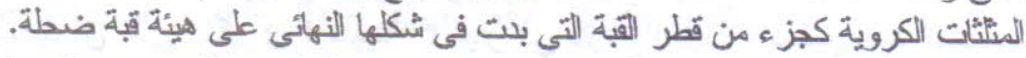

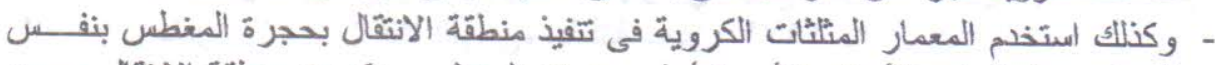

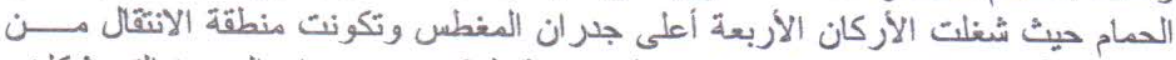

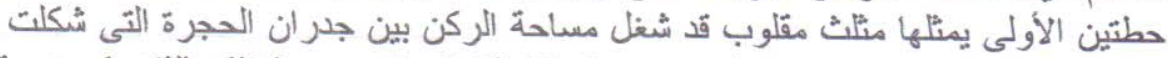

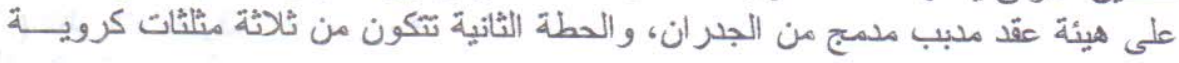


دراسات في آثار الوطن العربي

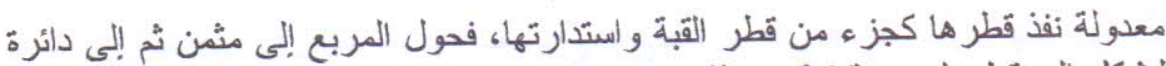

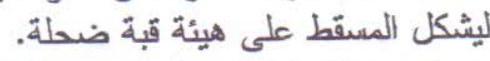

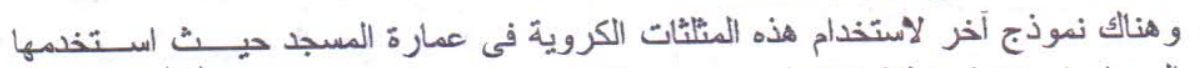

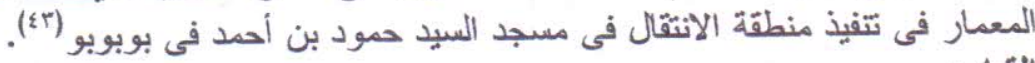

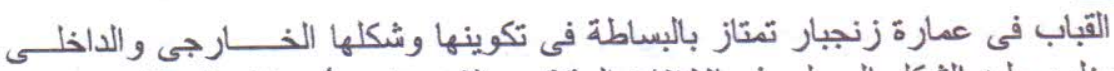

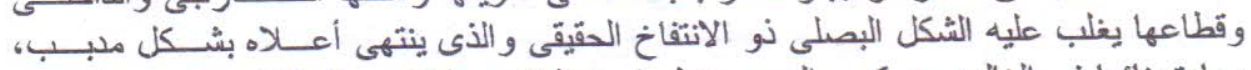

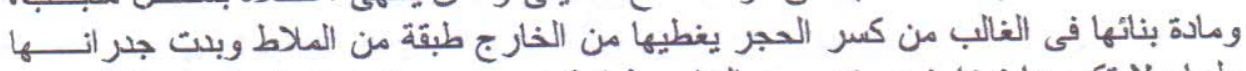

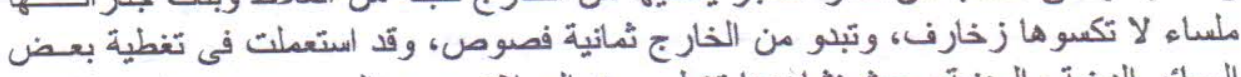

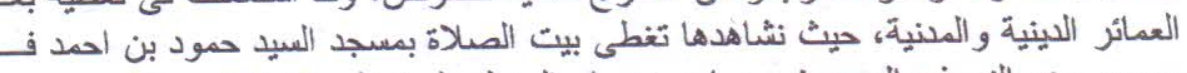

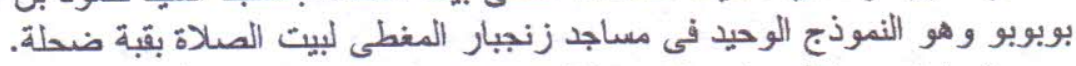

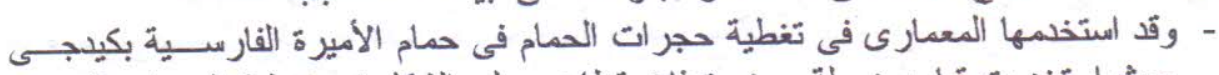

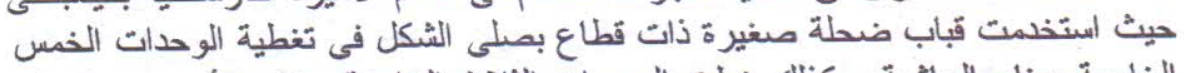

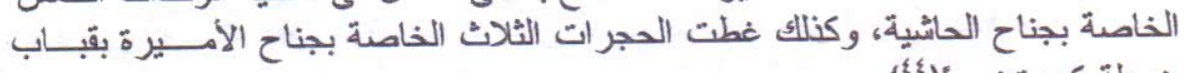
ضحلة كبيرة نسبياً(

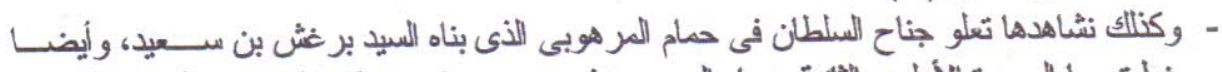

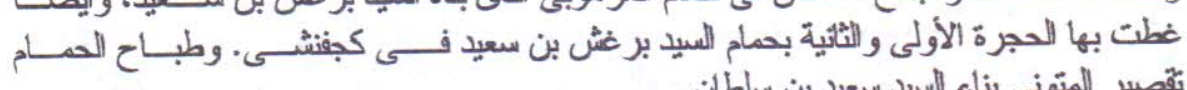
تقلقصير المتونى بناء السيد سعيد بن سلطان.

\section{مصادر البحث : مالبي \\ أولاي : المراجع العربية :}

(1) السيد رجب حر از : أفريقيا الثـــرقية والاسـتعمار الأوروبـي، دار النهضـــة

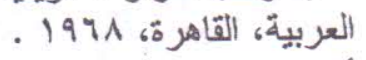

(ץ) ألفت يحى حموده : الطابع المعمارى بين التأصيل والمعاصره، الدار المصريــة

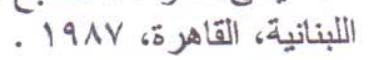
(T) نياو رينشارد برجير : من الحجارة إلى ناطحات السحاب، ترجمة محمد توفيق

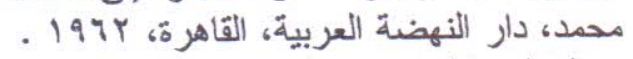

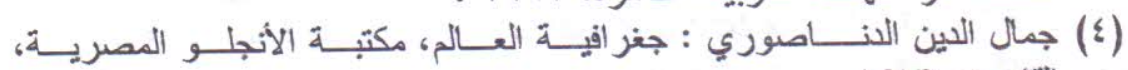

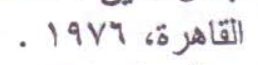
(0) جمال زكريا قاسم : ولة بولة بوسعيد فى عمان وشرق أفريقيــا، مكتبــة القـاهرة

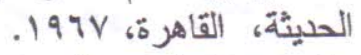

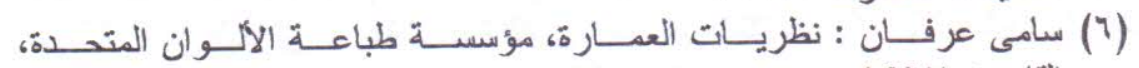

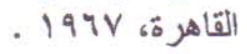

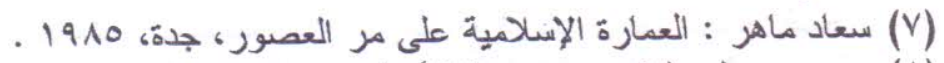

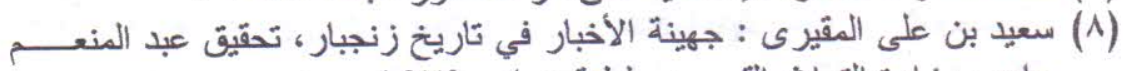

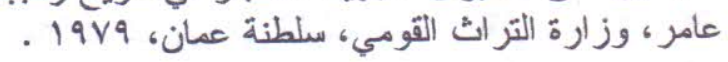

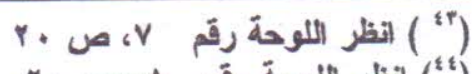

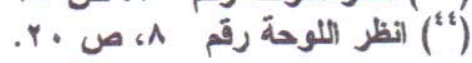


دراسات في آثار الوطن العربي

(9) شوقى عبد القوى عثمان : تجارة المحيط الهندى في عصر السيادة الإســلامية،

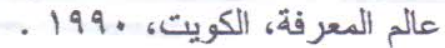

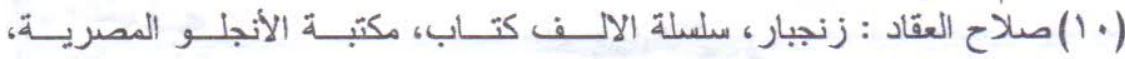

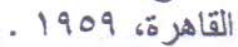

(1) عبد الغنى سعودى : إفريقيه، الجزء الثانى، مكتبة الأنجلو المصرية، القــــاهرة،

. 1909

(Y (I) عبد الرحمن عبد الكريم العانى : دور العمانيين في الملاحة والتجارة الإسـلامية

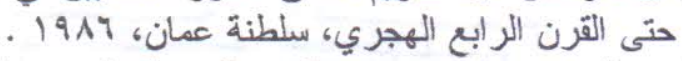

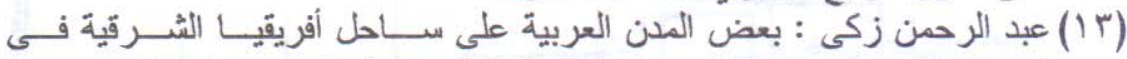

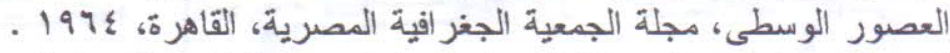

(؛ () فتحى ابو عيانه : سكان سلطنة عمان، دراسة ديوجر افية، مجلة دراسات الخئيج

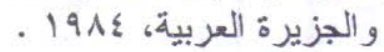

(10)فريد شافعى : العمارة العربية في مصر الإسلامية عصر الولاة، الهيئة العامــة

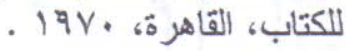

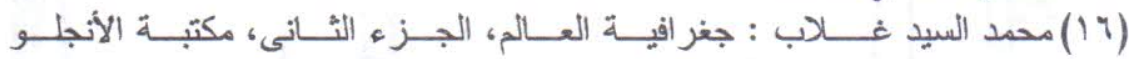

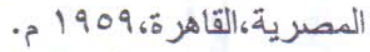

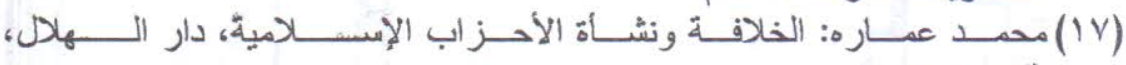

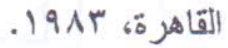

(1) (1) مصطفى بن إسماعيل المصري الآباضى : الهلية الإسلامية للملوك والأمـــراء

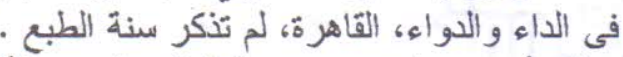

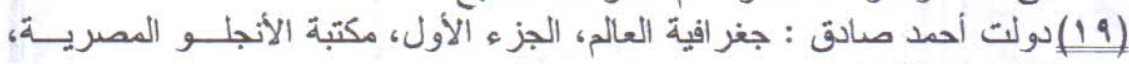

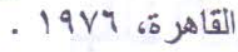

\section{ثنانيا : المراجيع الأجنيية :}

(1) Abdul Sheriff: Mosques, Merchant and Landouinery in Zangibar, Stan Town, Azania, 1992.

(2) Basil Davidson: The Loste cities of Africa, U.S.A, 1959.

(3) Coupland, R: East Africa and invaders from the Earliest Times to The death of Siyyd Said in 1956, Oxford, 1938.

(4) Pearce, F.B: Zanzibar the island metroplis of Eastern Africa, Canada, 1920.

(5) United Nations center for Human Setlements : The Stan Town of Zangibar, A technical report bar the Ministry of Lands, construction and Hallsin, Zangibar, April, 1983. 
دراسات في آثار الوطن العربي

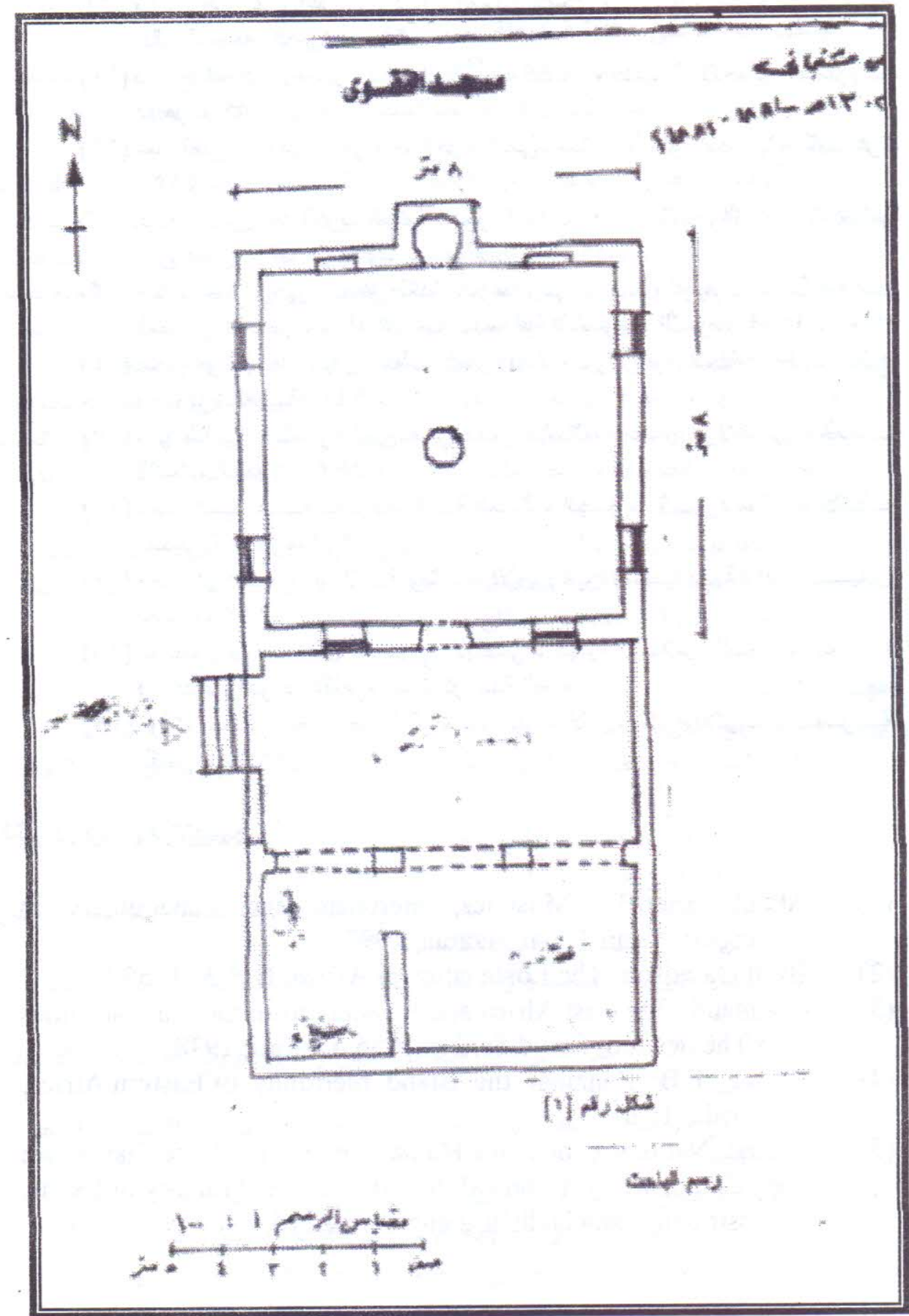

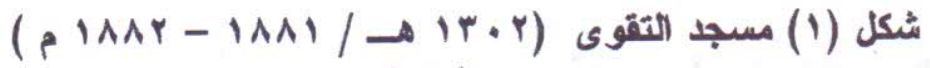

$$
\begin{aligned}
& \text { رسم الباحث }
\end{aligned}
$$


دراسات في آثار الوطن العربي

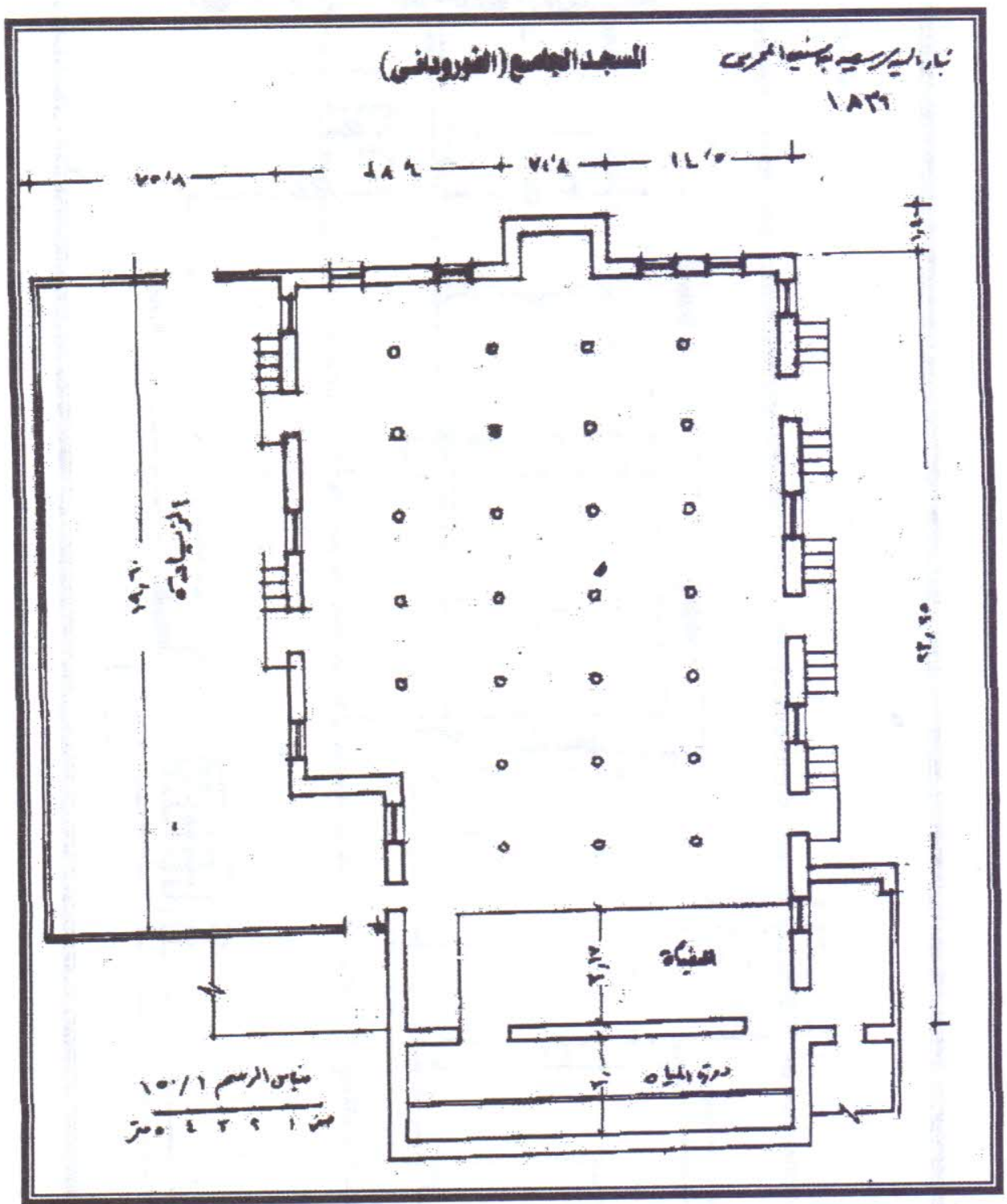

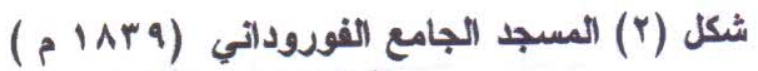

$$
\begin{aligned}
& \text { رسم الباحث المثود }
\end{aligned}
$$


مراسات في آثار الوطن العربي

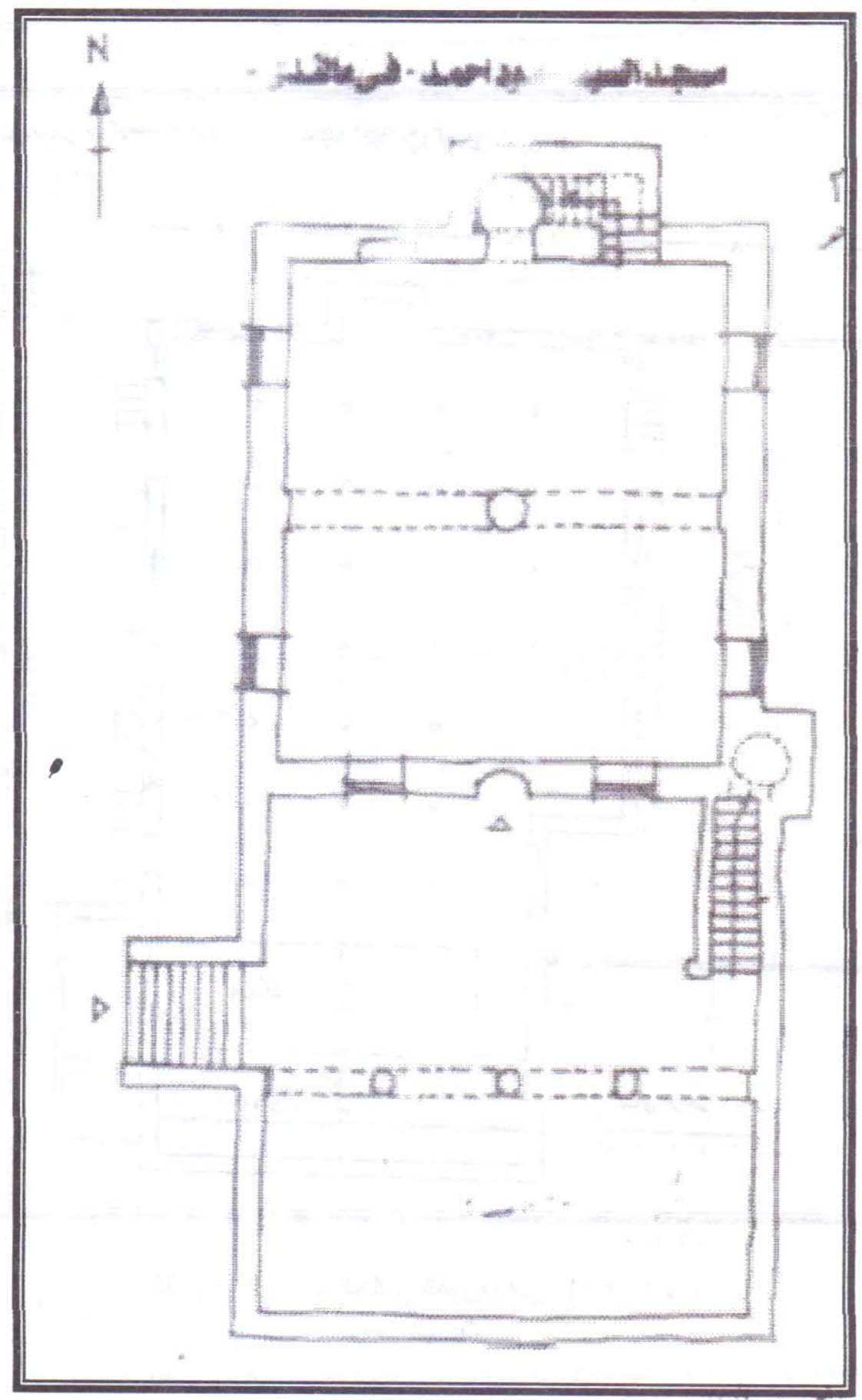

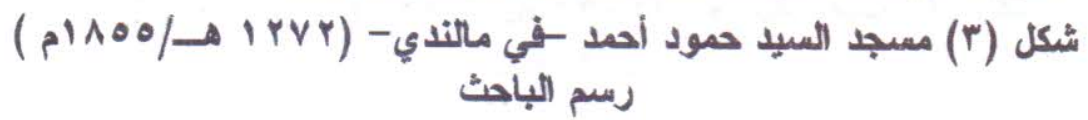


دراسات في آثار الوطن العربي

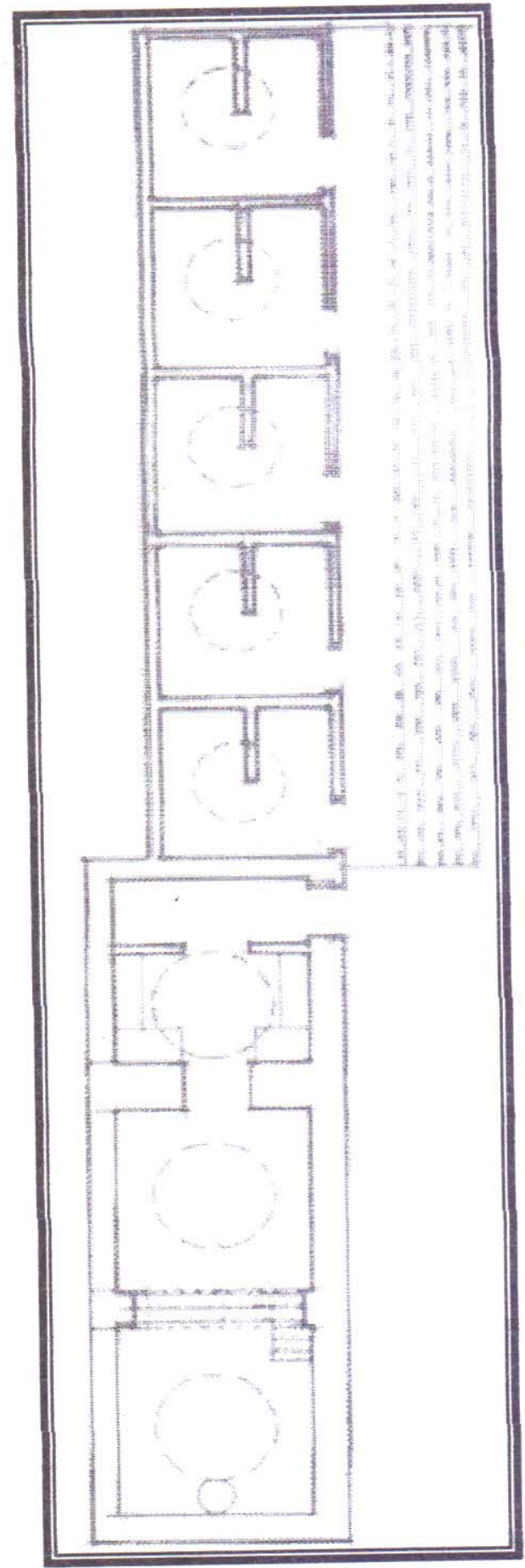

$$
\begin{aligned}
& \text { شكل (؛) حمام الأميرة الفارسية (بكيلجي ) ( } 1 \text { (19 م ) } \\
& \text { AFI }
\end{aligned}
$$


رراسات في آثار الوطن العربي

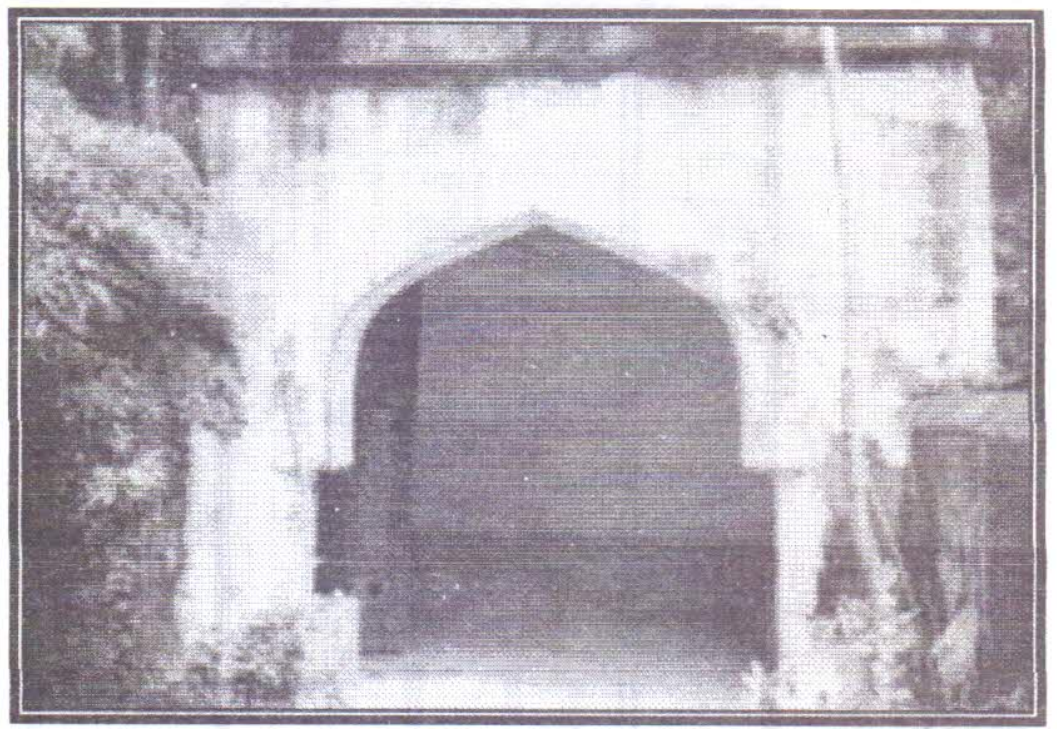

لوحة (1)مدخل مجموعة السيد حمود أحمد البوربعبدي في بوبويو

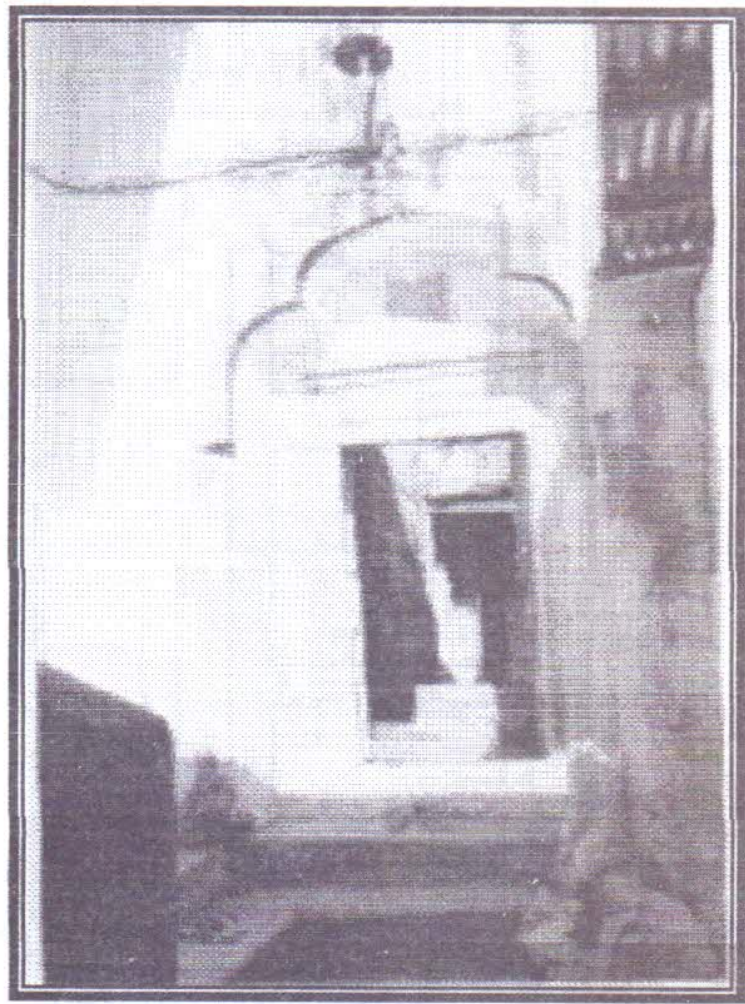

لوحة (Y) مسجد منارة المدخل الجنويب ذو العتّ المفصص 
راسات في آثار الوطن العربي

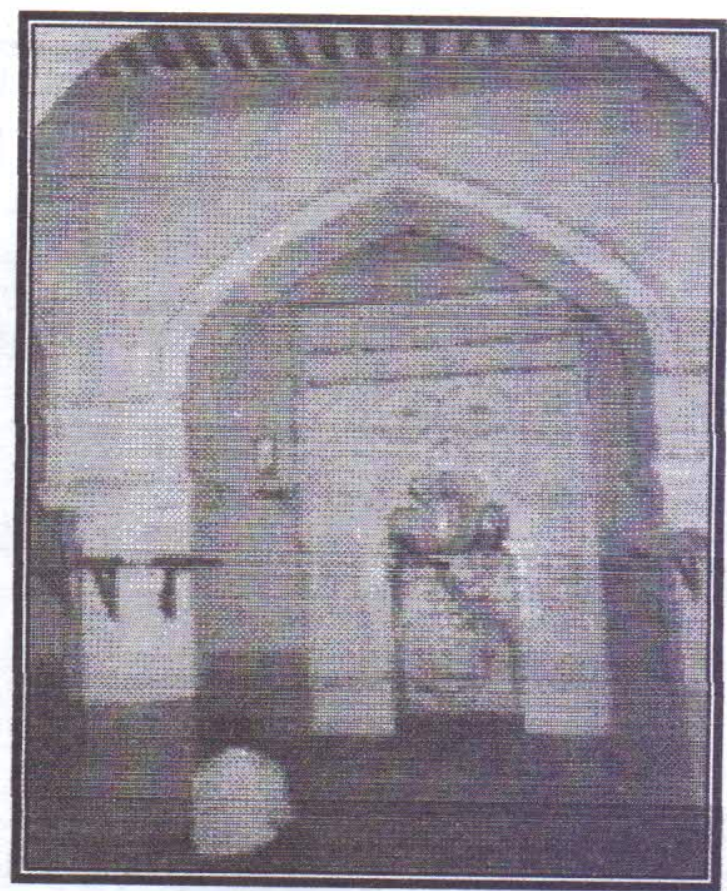

لوحة (r) مسجد حذيث - المحراب والعقد المفصص ذو الخمس فصوص

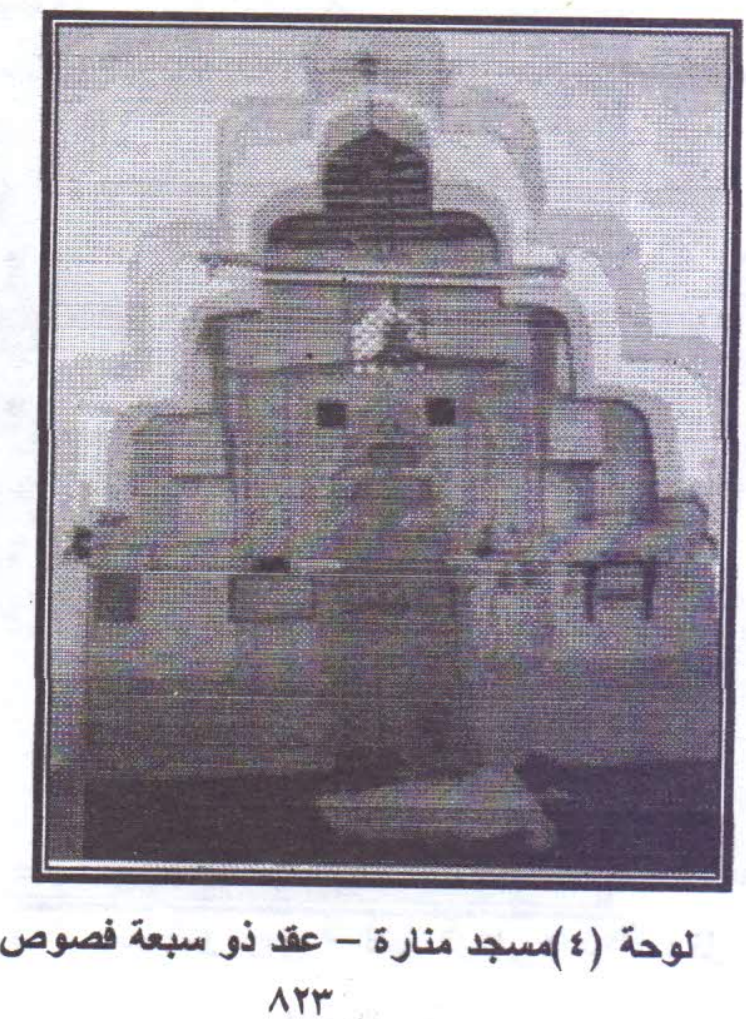


دراسات في آثار الوطن العربي

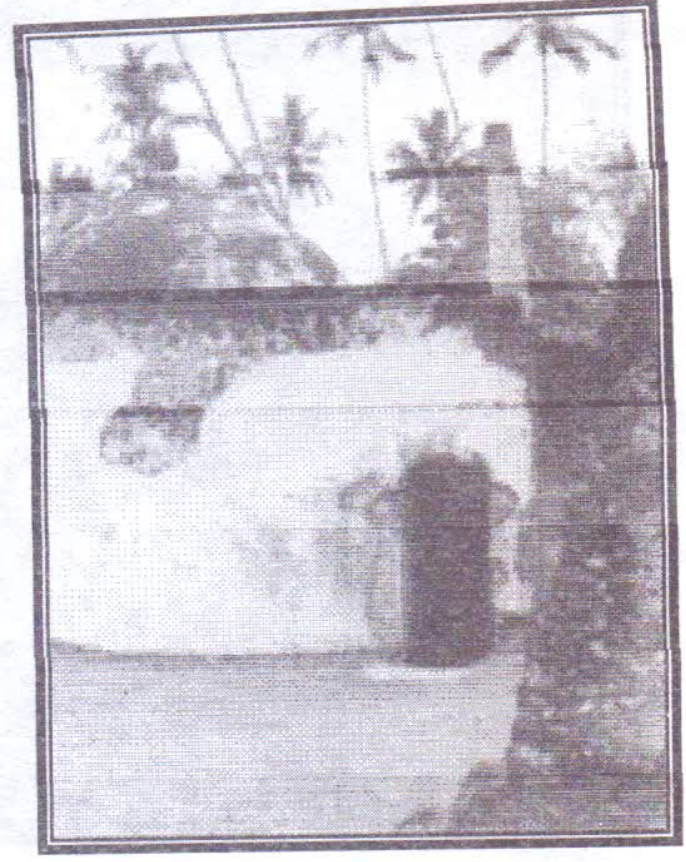

لوحة (0)حمام المرهوبي - مدخل الجناح السططاني

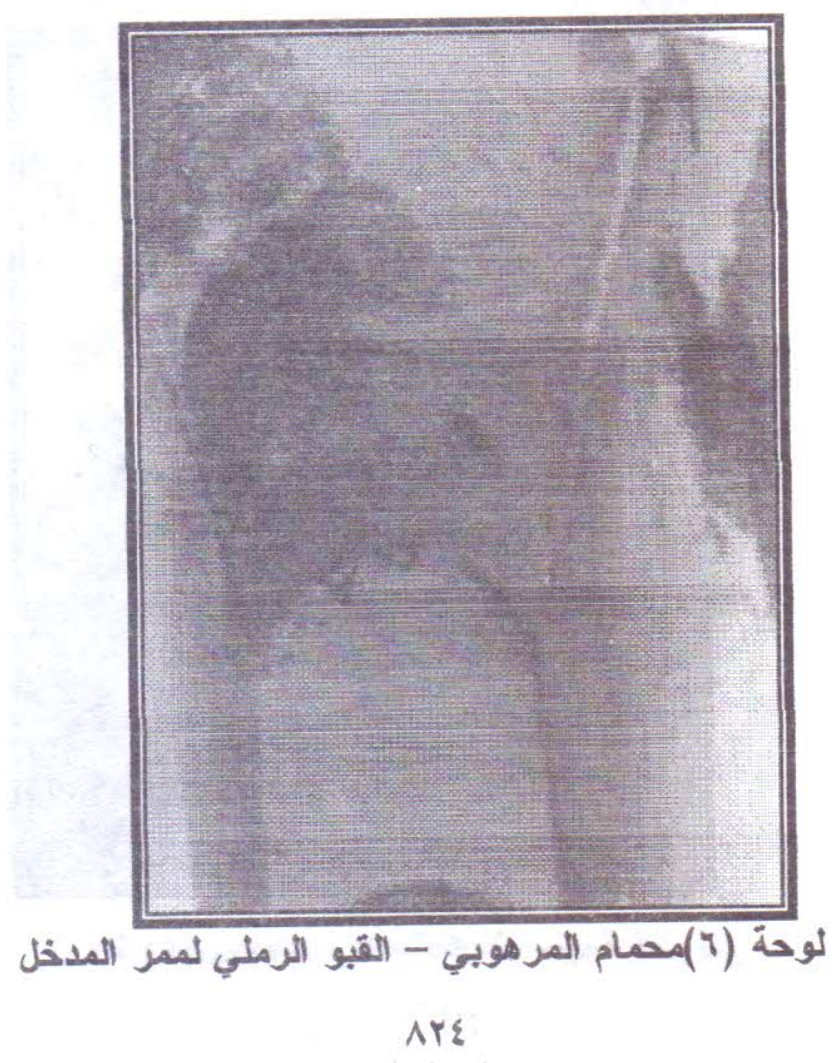


دراسات في آثار الوطن العربي

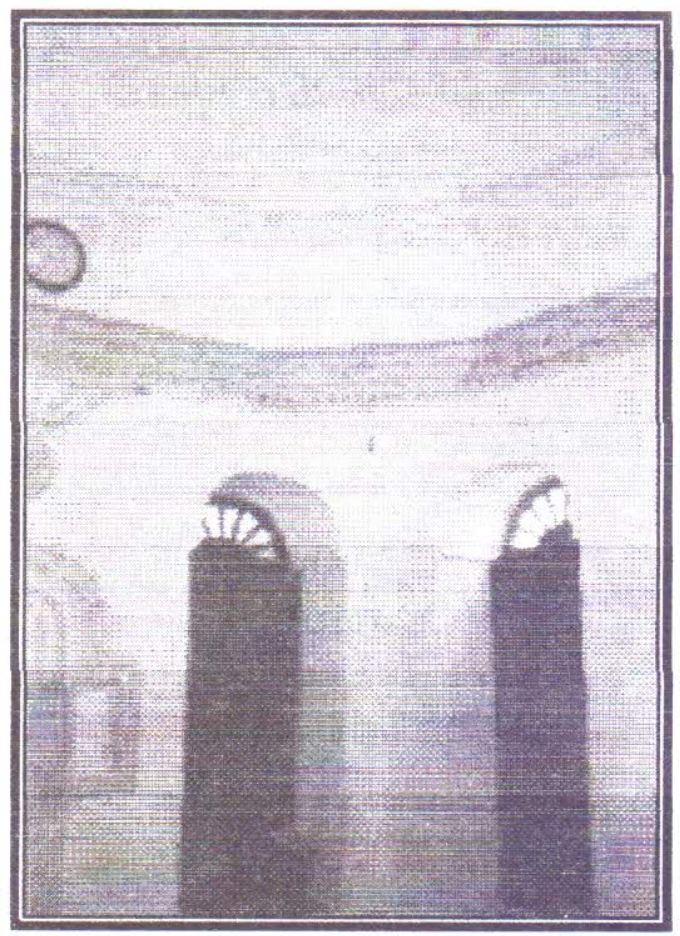

لوحة (V)مسجد السيد حمود أحمد في بويوبو - منطقة انتقال القبة

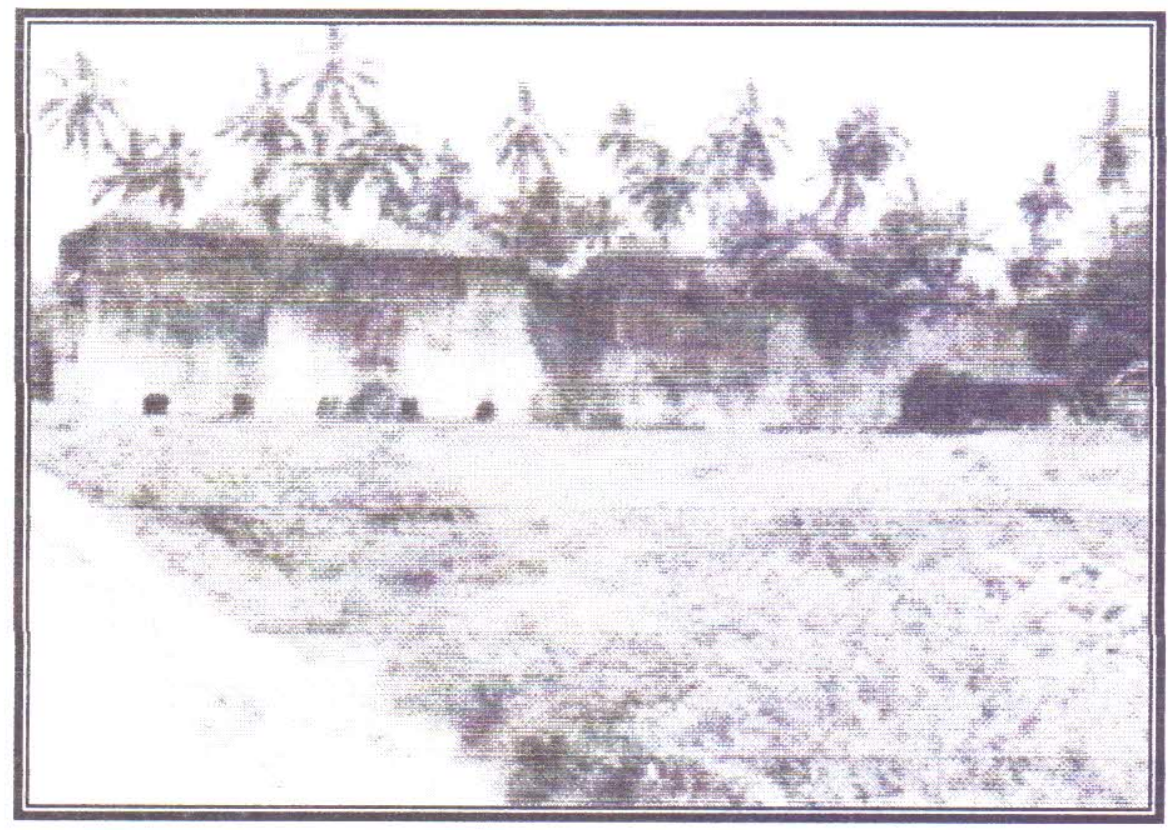

لوحة (^)قباب حمام الأميرة الفارسية (بكلاجي ) 